\title{
A Bulk Turbulent Air-Sea Flux Algorithm for High-Wind, Spray Conditions
}

\author{
EDGAR L ANDREAS \\ NorthWest Research Associates, Inc., Lebanon, New Hampshire \\ P. Ola G. Persson \\ Cooperative Institute for Research in Environmental Sciences, University of Colorado, and NOAA/ESRL/PSD, Boulder, Colorado
}

JEFFREY E. HARE

SOLAS International Project Office, School of Environmental Sciences, University of East Anglia, Norwich, United Kingdom

(Manuscript received 28 March 2007, in final form 15 October 2007)

\begin{abstract}
Sensible and latent heat can cross the air-sea interface by two routes: as interfacial fluxes controlled by molecular processes right at the interface, and as spray fluxes from the surface of sea spray droplets. Once the 10-m wind speed over the ocean reaches approximately $11-13 \mathrm{~m} \mathrm{~s}^{-1}$, the spray sensible and latent heat fluxes become significant fractions (i.e., $10 \%$ or greater) of the corresponding interfacial fluxes. The analysis here establishes that result by combining the Tropical Ocean-Global Atmosphere Coupled OceanAtmosphere Response Experiment (COARE) version 2.6 bulk interfacial flux algorithm with a microphysical spray model to partition measured heat fluxes from two good high-wind datasets into spray and interfacial flux contributions. The measurements come from the Humidity Exchange over the Sea (HEXOS) experiment and the Fronts and Atlantic Storm-Tracks Experiment (FASTEX); wind speeds in these two datasets span 5 to $20 \mathrm{~m} \mathrm{~s}^{-1}$.

After the measured heat fluxes are separated into spray and interfacial contributions, the spray fluxes are used to develop a fast spray flux algorithm to combine with the COARE version 2.6 interfacial flux algorithm in a unified turbulent surface flux algorithm for use in large-scale and ocean storm models. A sensitivity analysis of the spray and interfacial components of this unified flux algorithm demonstrates how the two component fluxes scale differently with the mean meteorological variables and why they must therefore be parameterized separately in models intended to treat air-sea fluxes in high winds.
\end{abstract}

\section{Introduction}

As the surface-level wind speed increases above $10 \mathrm{~m} \mathrm{~s}^{-1}$, the physics of turbulent air-sea heat transfer changes. In low winds, the turbulent heat transfer occurs almost exclusively at the air-sea interface. But with increasing wind speed, sea spray production increases, and now heat and moisture transfer also occurs at the surface of the spray droplets. We refer to these two ways by which air and sea exchange sensible and latent heat as the interfacial and spray routes.

The fluxes via these two routes scale differently

Corresponding author address: Dr. Edgar L Andreas, NorthWest Research Associates, Inc., 25 Eagle Ridge, Lebanon, NH 03766-1900.

E-mail: eandreas@nwra.com
(Andreas 1994; Andreas and DeCosmo 2002). For example, although the Tropical Ocean-Global Atmosphere Coupled Ocean-Atmosphere Response Experiment (COARE) version 3.0 bulk flux algorithm (Fairall et al. 2003) has been tuned with flux data collected in wind speeds up to $20 \mathrm{~m} \mathrm{~s}^{-1}$ and is therefore operationally useful in this wind speed range, it is based strictly on interfacial scaling and thus may not be reliable if it is extrapolated to wind speeds above $20 \mathrm{~m} \mathrm{~s}^{-1}$. Here, on the other hand, we present a new bulk flux algorithm that explicitly acknowledges the two routes by which heat and moisture cross the air-sea interface. Because we base algorithms for both flux routes on theory and tune the new spray algorithm with data, we expect our algorithm to be reliable on extrapolation to high wind speeds, where flux predictions are essential but validation data do not exist. 
We develop our algorithm using data from the $\mathrm{Hu}-$ midity Exchange over the Sea (HEXOS) experiment (Katsaros et al. 1987; Smith et al. 1996; DeCosmo et al. 1996), and the Fronts and Atlantic Storm-Tracks Experiment (FASTEX; Joly et al. 1997; Persson et al. 2005), two of the best available high-wind-speed datasets. Our analysis first uses Andreas's spray microphysics model (Andreas 1989, 1990, 1992) and the COARE version 2.6 interfacial flux algorithm (Fairall et al. 1996b) to separate the measured HEXOS and FASTEX sensible and latent heat fluxes into interfacial and spray contributions. Identifying these interfacial and spray flux components is our key scientific issue. Only Andreas and DeCosmo $(1999,2002)$ have demonstrated this partitioning before, with the HEXOS data.

Next, we fit the spray sensible and latent heat fluxes that we have isolated with parameterizations that allow quick predictions of these fluxes from bulk oceanic and meteorological variables. Our resulting bulk flux algorithm thus comprises the COARE version 2.6 algorithm for the interfacial fluxes and the new algorithm for the spray fluxes. Andreas (2003, 2004a) and Andreas et al. (2007) reported preliminary versions of this algorithm.

Here is a preview of how the interfacial and spray components scale differently. The interfacial fluxes increase almost linearly with the wind speed, but the spray fluxes increase faster than the square of the friction velocity. Likewise, the interfacial sensible heat flux scales with the air-sea temperature difference, but the spray sensible heat flux scales with the difference between the sea surface temperature and the equilibrium temperature of spray droplets starting with a radius of $100 \mu \mathrm{m}$. This latter temperature depends on relative humidity and is almost always lower than the air temperature. Consequently, with no air-sea temperature difference, there is no interfacial sensible heat flux, but usually there is still a spray sensible heat flux. Finally, the interfacial latent heat flux scales with the difference between the specific humidity at the ocean surface and at some reference height, and the spray latent heat flux scales with the mass lost by evaporating spray droplets of initial radius $50 \mu \mathrm{m}$ during their short lifetime between creation and their plunge back into the sea.

\section{Spray heat flux model}

\section{a. Microphysics}

Most of the heat and moisture transfer mediated by spray occurs within a near-surface region that we call the droplet evaporation layer. This layer typically extends about one significant wave height above mean sea level (Andreas et al. 1995; Van Eijk et al. 2001). Spray droplets ejected into this layer start with an initial radius $r_{0}$ and the same temperature as the surface seawater $T_{\mathrm{s}}$, evolve in both temperature and radius during a brief flight of duration $\tau_{f}$, and fall back into the sea. This is our conceptual picture of spray-mediated heat and moisture transfer (e.g., Andreas and DeCosmo 1999, 2002).

Under constant environmental conditions, droplet temperature $T$ and radius $r$ evolve as functions of time $t$ approximately as (Andreas 1989, 1990, 2005a; Andreas and DeCosmo 1999, 2002)

$$
\frac{T(t)-T_{\mathrm{eq}}}{T_{s}-T_{\mathrm{eq}}}=\exp \left(-t / \tau_{T}\right)
$$

and

$$
\frac{r(t)-r_{\mathrm{eq}}}{r_{0}-r_{\mathrm{eq}}}=\exp \left(-t / \tau_{r}\right) .
$$

Here, $T_{\text {eq }}$ is the evaporating or equilibrium temperature of a saline droplet with initial radius $r_{0}$ and initial temperature $T_{s}, r_{\mathrm{eq}}$ is the corresponding equilibrium radius of a droplet with initial radius $r_{0}$, and $\tau_{T}$ and $\tau_{r}$ are the $e$-folding times that give the rates for these temperature and radius changes.

Our values for $T_{\text {eq }}, r_{\text {eq }}, \tau_{T}$, and $\tau_{r}$ here come from Andreas's (1989, 1990, 1992, 1995) full microphysical spray model, but Andreas (2005a) recently reported algorithms for quickly calculating these four microphysical parameters for use in the flux algorithm that we develop here. Briefly, all four quantities depend on sea surface temperature $\left(T_{s}\right)$, air temperature $\left(T_{a}\right)$, relative humidity $(\mathrm{RH})$, surface salinity, and initial droplet radius.

Figure 1 shows one example of how spray droplet temperature and radius evolve (cf. Andreas 1990, 1995). With this figure, we also demonstrate two essential points that are fundamental to our sea spray flux algorithm. First, droplet temperature evolves much faster than droplet radius. That is, for all radii and for all environmental conditions, $\tau_{r}$ is typically three orders of magnitude longer than $\tau_{T}$. Consequently, the spraymediated sensible and latent heat transfers are decoupled; evaporation does not really begin until the droplet is sitting at $T_{\text {eq }}$. Second, $T_{\text {eq }}$ is usually significantly less than the air temperature, and this difference increases with falling relative humidity (cf. Andreas 1995).

Within this microphysical framework, we rearrange (2.1) to estimate the temperature of a spray droplet when it falls back into the sea (at time $\tau_{f}$ ) as

$$
T\left(\tau_{f}\right)=T_{\mathrm{eq}}+\left(T_{s}-T_{\mathrm{eq}}\right) \exp \left(-\tau_{f} / \tau_{T}\right) .
$$




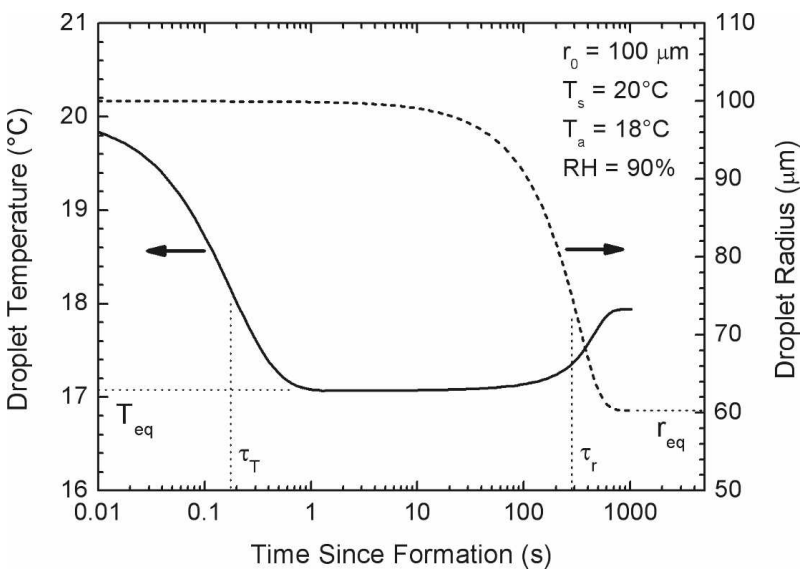

FIG. 1. Temperature and radius evolution of a spray droplet with initial radius $100 \mu \mathrm{m}\left(r_{0}\right)$, initial temperature $20^{\circ} \mathrm{C}\left(T_{s}\right)$, and initial salinity $34 \mathrm{psu}$. This droplet is flung into air with temperature $18^{\circ} \mathrm{C}\left(T_{a}\right)$ and relative humidity $90 \%(\mathrm{RH})$; the barometric pressure is $1000 \mathrm{mb}$. The microphysical quantities $T_{\mathrm{eq}}, r_{\mathrm{eq}}, \tau_{T}$, and $\tau_{r}$ characterize the evolution [see (2.1) and (2.2)].

This function, of course, does not model the droplet's warming depicted as the upward tail on the right end of the temperature trace in Fig. 1. This shortcoming is immaterial, though, because the larger droplets that carry most of the sensible heat (shown later in Fig. 2) do not usually remain suspended long enough to reach this warming stage (e.g., Andreas and DeCosmo 1999).

From (2.3), the rate at which all droplets of initial radius $r_{0}$ transport sensible heat across the air-sea interface is (Andreas 1992)

$$
Q_{S}\left(r_{0}\right)=\rho_{s} c_{\mathrm{ps}}\left(T_{s}-T_{\mathrm{eq}}\right)\left[1-\exp \left(-\tau_{f} / \tau_{T}\right)\right]\left(\frac{4 \pi r_{0}^{3}}{3} \frac{d F}{d r_{0}}\right) .
$$

Here, $\rho_{s}$ is the density of seawater, and $c_{\mathrm{ps}}$ is the specific heat of seawater.

Also in (2.4), $d F / d r_{0}$, the spray generation function, is the rate at which droplets of radius $r_{0}$ are produced at the sea surface. It has units of number of droplets with radius $r_{0}$ produced per square meter of sea surface per second per micrometer increment in droplet radius, that is, $\mathrm{m}^{-2} \mathrm{~s}^{-1} \mu \mathrm{m}^{-1}$. Andreas (2002a) reviewed the $d F / d r_{0}$ functions available in the literature and recommended the function given by Fairall et al. (1994). Their function is what we use for $d F / d r_{0}$ here. In our earlier analysis, Andreas and DeCosmo (2002) had used the Andreas (1992) spray generation function.

Similar arguments lead to an estimate of the latent heat carried by droplets of initial radius $r_{0}$. For $\tau_{f} \leq \tau_{r}$, (2.2) implies that droplets of initial radius $r_{0}$ fall back into the sea with radius

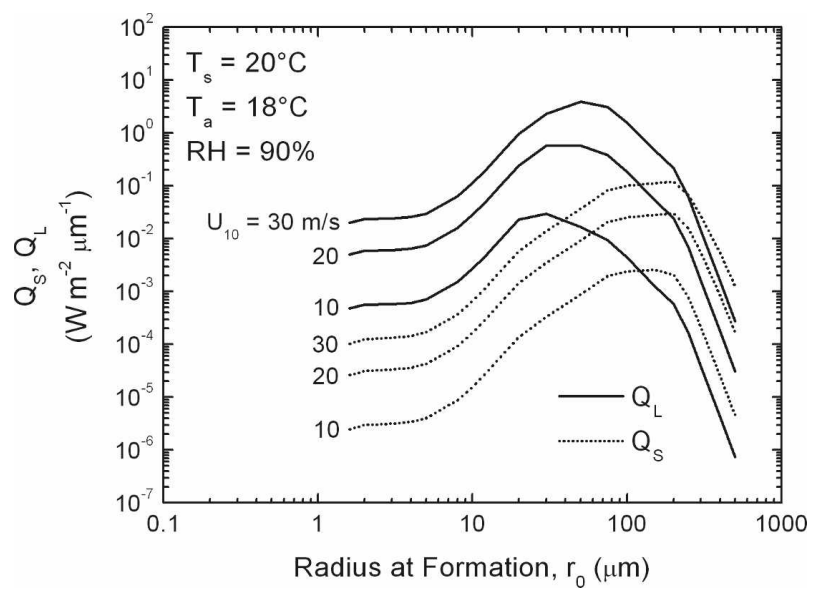

FIG. 2. The radius-specific spray sensible $\left(Q_{S}\right)$ and latent $\left(Q_{L}\right)$ heat fluxes [from (2.4) and (2.6)] as functions of the radius at formation $\left(r_{0}\right)$ for three values of the wind speed at a $10-\mathrm{m}$ reference height $\left(U_{10}\right)$. For these calculations, the water temperature $\left(T_{s}\right)$ is $20^{\circ} \mathrm{C}$, the air temperature $\left(T_{a}\right)$ is $18^{\circ} \mathrm{C}$, the $\mathrm{RH}$ is $90 \%$, the barometric pressure is $1000 \mathrm{mb}$, and the surface salinity is $34 \mathrm{psu}$.

$$
r\left(\tau_{f}\right)=r_{\mathrm{eq}}+\left(r_{0}-r_{\mathrm{eq}}\right) \exp \left(-\tau_{f} / \tau_{r}\right) .
$$

These droplets, therefore, transfer latent heat at the rate

$$
Q_{L}\left(r_{0}\right)=\rho_{s} L_{v}\left\{1-\left[\frac{r\left(\tau_{f}\right)}{r_{0}}\right]^{3}\right\}\left(\frac{4 \pi r_{0}^{3}}{3} \frac{d F}{d r_{0}}\right) \quad \text { for } \quad \tau_{f} \leq \tau_{r},
$$

where $L_{v}$ is the latent heat of vaporization.

If the relative humidity is $95 \%$ or less, droplets for which $\tau_{f}>\tau_{r}$ will have experienced at least two-thirds of their potential moisture loss before they fall back into the sea (Andreas 1992). For these droplets, we simply assume that $\tau_{f} \gg \tau_{r}$ and, from (2.5), approximate the rate at which they exchange latent heat as

$$
Q_{L}\left(r_{0}\right)=\rho_{s} L_{v}\left[1-\left(\frac{r_{\mathrm{eq}}}{r_{0}}\right)^{3}\right]\left(\frac{4 \pi r_{0}^{3}}{3} \frac{d F}{d r_{0}}\right) \text { for } \tau_{f}>\tau_{r} .
$$

By integrating $Q_{S}\left(r_{0}\right)$ and $Q_{L}\left(r_{0}\right)$ over all radii, we get what Andreas and DeCosmo $(1999,2002)$ called the "nominal" spray sensible and latent heat fluxes:

$$
\begin{aligned}
& \bar{Q}_{S}=\int_{r_{1}}^{r_{2}} Q_{S}\left(r_{0}\right) d r_{0}, \\
& \bar{Q}_{L}=\int_{r_{1}}^{r_{2}} Q_{L}\left(r_{0}\right) d r_{0},
\end{aligned}
$$

where $r_{1}$ and $r_{2}$ are the smallest and largest droplets that contribute significantly to the integrals. For the 
Fairall et al. (1994) spray generation function that we use here, $r_{1}=1.6 \mu \mathrm{m}$ and $r_{2}=500 \mu \mathrm{m}$.

Figure 2 shows examples of $Q_{S}\left(r_{0}\right)$ and $Q_{L}\left(r_{0}\right)$ for several wind speeds. These quantities have units $\mathrm{W} \mathrm{m}{ }^{-2} \mu \mathrm{m}^{-1}$. Integrating under these curves over all radii gives the nominal fluxes $\bar{Q}_{S}$ and $\bar{Q}_{L}$ in (2.7). These quantities represent the total fluxes that spray would carry across the air-sea interface if no other processes were important. Because $\bar{Q}_{S}$ and $\bar{Q}_{L}$ are microphysically based, they should have proper theoretical dependence on temperature, humidity, and wind speed. Nevertheless, they are still "nominal," primarily because of the uncertainty in $d F / d r_{0}$ (Andreas 2002a). Hence, we ultimately tune these theoretical relationships with data to remove the qualifier nominal.

To estimate the droplet lifetime $\tau_{f}$, Andreas (1992) introduced

$$
\tau_{f}=\frac{H_{1 / 3}}{2 u_{f}\left(r_{0}\right)},
$$

where $H_{1 / 3}=2 A_{1 / 3}$ is the significant wave height, $A_{1 / 3}$ is the significant wave amplitude, and $u_{f}\left(r_{0}\right)$ is the terminal fall speed for droplets of radius $r_{0}$ (Friedlander 1977, p. 105; Clift et al. 1978, 33ff.; Andreas 1989, 1990). This expression presumes that spume droplets dominate the heat transfer in (2.7). These are torn right off the wave crests and are large enough to free-fall back into the sea with negligible turbulent suspension.

Lagrangian and Eulerian models of spray droplet dispersion by Edson (Andreas et al. 1995; Edson et al. 1996) and Van Eijk et al. (2001), respectively, support the choice of $H_{1 / 3}$ as the relevant height scale for the droplet evaporation layer. Mestayer et al. (1996), however, believe that $H_{1 / 3}$ is too large for this scale, while Kepert et al. (1999) suggest that it is too small.

Both the HEXOS and FASTEX datasets include measurements of $H_{1 / 3}$ that were coincident with the flux measurements. For the analysis described in section $4 \mathrm{~b}$, we used these wave heights to evaluate $\tau_{f}$ from (2.8).

If no such wave measurements are available, the spray flux algorithm that we develop in section 5 includes a parameterization that Andreas and Wang (2007) developed for $H_{1 / 3}$ as a function of the 10-m wind speed. Alternatively, if our algorithm is used in a coupled atmosphere-ocean model that also includes a wave model, the significant wave height from that model should be used in (2.8).

\section{b. Estimating total heat fluxes}

A basic hypothesis in our analysis is that the total sensible $\left(H_{s, T}\right)$ and latent $\left(H_{L, T}\right)$ heat fluxes that would be measured, say, with eddy-correlation instruments placed above the droplet evaporation layer are simply linear sums of the interfacial and spray contributions. Taking $\bar{Q}_{S}$ and $\bar{Q}_{L}$ from (2.7) as the nominal spray fluxes, we formulate this hypothesis as (cf. Fairall et al. 1994; Edson and Andreas 1997; Andreas and DeCosmo 1999, 2002)

$$
\begin{aligned}
& H_{L, T}=H_{L}+\alpha \bar{Q}_{L}, \\
& H_{s, T}=H_{S}+\beta \bar{Q}_{S}-(\alpha-\gamma) \bar{Q}_{L} .
\end{aligned}
$$

Here, $H_{L}$ and $H_{s}$ are estimates of the interfacial latent and sensible heat fluxes that we compute with our adaptation of the COARE version 2.6 algorithm, which we describe in appendix A. Here also, $\alpha, \beta$, and $\gamma$ are small, nonnegative coefficients that we use to tune the nominal spray fluxes to data.

In (2.9a), the $\alpha$ term models the latent heat flux (or the moisture flux) coming out the top of the droplet evaporation layer that spray has contributed. Fairall et al. (1994), however, point out that because the atmosphere must supply all the heat to evaporate the droplets, these droplets are a sink for sensible heat. Hence, to conserve energy, the $\alpha$ term in (2.9a) must appear with the opposite sign in the sensible heat equation, $(2.9 \mathrm{~b})$.

The $\beta$ term in (2.9b) models the sensible heat that spray droplets give up in cooling from the ocean surface temperature $T_{\mathrm{s}}$ to the temperature they have on returning to the sea, namely, $T\left(\tau_{f}\right)$ from (2.3). Some models (e.g., Makin 1998) ignore this term because $\bar{Q}_{S}$ is typically much smaller than $\bar{Q}_{L}$ (see Fig. 2), but Andreas and Emanuel (2001) focus on it as the likely route by which spray affects the total air-sea enthalpy flux.

Katsaros and DeCosmo (1990), Smith (1990), Katsaros and de Leeuw (1994), Andreas et al. (1995), and DeCosmo et al. (1996) further speculate that feedbacks within the droplet evaporation layer modify the interfacial fluxes represented by $H_{s}$ and $H_{L}$ in (2.9). For example, evaporating droplets cool the droplet evaporation layer and thereby increase the near-surface temperature gradient; the interfacial sensible heat flux would then be larger than the $H_{s}$ value computed from surface temperature and an air temperature measured above the droplet evaporation layer. We add the $\gamma$ term in (2.9b) to account for this feedback and expect $\gamma<\alpha$.

A similar process could affect the total latent heat flux. Evaporating spray would moisten the near-surface atmosphere and thereby decrease the near-surface humidity gradient. The actual interfacial latent heat flux would then be smaller than the $H_{L}$ value computed using the difference between specific humidities measured at the surface and above the droplet evaporation layer. We do not, however, see a way to separate this 
effect from the spray-mediated flux. Consequently, the $\alpha$ term in (2.9a) possibly includes both the direct spray effect and the humidity feedback effect.

In light of the above discussion, the total enthalpy flux from the ocean to the atmosphere is the sum of $H_{L, T}$ and $H_{s, T}$ :

$$
H_{L, T}+H_{s, T}=H_{L}+H_{s}+\beta \bar{Q}_{S}+\gamma \bar{Q}_{L} .
$$

This flux is the lower boundary condition in atmospheric models and is, for example, the energy that drives tropical storms (Businger 1982; Emanuel 1995). Notice here that the direct spray latent heat flux, the $\alpha$ $\bar{Q}_{L}$ term in (2.9a), disappears when we add (2.9a) and (2.9b); only the spray latent heat feedback (the $\gamma$ term) remains. But the direct spray sensible heat flux, the $\beta$ $\bar{Q}_{S}$ term, survives the summation and thus is likely the main route by which spray affects storm energetics (cf. Andreas and Emanuel 2001).

\section{Data}

In our earlier work on partitioning interfacial and spray contributions to the sensible and latent heat fluxes, we used the HEXOS data exclusively (Andreas and DeCosmo 1999, 2002; Andreas 2003, 2004a). DeCosmo (1991), Smith et al. (1992), Katsaros et al. (1994), and DeCosmo et al. (1996) described this dataset and the instruments used to obtain it. Briefly, the HEXOS data were collected in the North Sea from the Meetpost Noordwijk platform, where the water is only $18 \mathrm{~m}$ deep. The HEXOS set contains 175 runs in which the turbulent fluxes of momentum and sensible and latent heat were measured by eddy correlation in $10-\mathrm{m}$ winds up to $18.3 \mathrm{~m} \mathrm{~s}^{-1}$. Many of the runs include two measurements of the latent heat flux-one using a Lyman- $\alpha$ hygrometer and the other using wet and dry thermocouples. Each run also includes measurements of the significant wave height. Andreas and DeCosmo (2002) described some preprocessing that we had to do on DeCosmo's (1991) tabulated data to obtain the variables we required.

Here, we add the FASTEX turbulent flux data (Persson et al. 2005) to our analysis. These deep-ocean data come from a mast placed on the bow of the R/V Knorr as the ship crossed the North Atlantic from England to Nova Scotia at latitudes between $52^{\circ}$ and $40^{\circ} \mathrm{N}$ from 23 December 1996 to 26 January 1997. We rigorously edited these data and retained for our analysis only periods when the ship was nearly stationary and headed into the wind (and waves).

The FASTEX set includes 322 hourly eddy-correlation measurements of the momentum and sensible and latent heat fluxes with a sonic anemometer and an
Ophir hygrometer mounted at 19.2 and $17.5 \mathrm{~m}$, respectively, above the nominal water line. The sonic anemometer recorded average wind speeds of up to $22 \mathrm{~m} \mathrm{~s}^{-1}$ during the transect. The dataset also includes simultaneous measurements of the significant wave height, which was between 2.0 and $5.5 \mathrm{~m}$ for the flux data that we use in our analysis. As with the HEXOS set, we use this measurement in (2.8).

Besides the turbulent fluxes, both the HEXOS and FASTEX sets include accompanying measurements of mean meteorological quantities, such as wind speed, humidity, and air and sea surface temperature. In our flux partitioning, which is based on (2.9), we assume that $H_{L, T}$ and $H_{s, T}$ are the reported HEXOS and FASTEX latent and sensible heat fluxes. We compute the nominal fluxes $\bar{Q}_{L}$ and $\bar{Q}_{S}$ by using the microphysical model (described in section 2a) and these mean meteorological quantities. We also use the mean meteorological quantities in the flux algorithm described in appendix A to compute the interfacial fluxes in (2.9), $H_{L}$ and $H_{s}$.

In analyzing the FASTEX data, we used the interfacial algorithm as it is described in appendix A. Because the HEXOS site was in only $18 \mathrm{~m}$ of water, however, (A.5) is not the best parameterization for predicting the roughness length $z_{0}$. Therefore, for the HEXOS analysis, we estimated $z_{0}$ from the drag relation found specifically for the HEXOS site (Smith et al. 1992; cf. Andreas and DeCosmo 2002):

$$
C_{\mathrm{DN} 10}=\left(0.27+0.116 U_{\mathrm{N} 10}\right) \times 10^{-3} .
$$

Here, $C_{\mathrm{DN} 10}$ is the neutral-stability drag coefficient at a reference height of $10 \mathrm{~m}$, and $U_{\mathrm{N} 10}$ is the neutralstability wind speed (in $\mathrm{m} \mathrm{s}^{-1}$ ) at $10 \mathrm{~m}$. The HEXOS dataset includes $U_{\mathrm{N} 10}$. With (3.1), our estimate of the roughness length for the HEXOS analysis is

$$
z_{0}=10 \exp \left(-k C_{\mathrm{DN} 10}^{-1 / 2}\right),
$$

which gives $z_{0}$ in meters. All other aspects of our HEXOS analysis were as described in appendix A.

The surface salinity affects the four microphysical constants $T_{\text {eq }}, r_{\text {eq }}, \tau_{T}$, and $\tau_{r}$. We also included salinity effects when we calculated the surface specific humidity, $Q_{s}$ in (A.1c). For the HEXOS site, we used a surface salinity of $34 \mathrm{psu}$; for the FASTEX transect, we used 36 psu.

\section{Separating spray and interfacial fluxes}

\section{a. Without spray}

To justify our focus on spray effects, we first state the null hypothesis: The HEXOS and FASTEX heat flux 
data are well represented by an interfacial flux algorithm. If this hypothesis were true, a state-of-the-art bulk flux algorithm that parameterizes only interfacial heat transfer should be able to reproduce both datasets. COARE version 2.6 is such an algorithm; it is based on a theory that recognizes only interfacial heat transfer (i.e., Liu et al. 1979) and is well validated for wind speeds up to $10 \mathrm{~m} \mathrm{~s}^{-1}$ (e.g., Fairall et al. 1996b; Grant and Hignett 1998; Chang and Grossman 1999; Brunke et al. 2002), where, we believe, interfacial transfer dominates.

Figure 3, however, shows the results when we model the HEXOS and FASTEX sets with the interfacial flux algorithm described in appendix A. That is, we invoke (2.9) but exclude spray effects by setting $\alpha=\beta=\gamma=0$. Figure 3 depicts the ratio of the measured flux $\left(H_{L, T}\right.$ or $\left.H_{s, T}\right)$ to the modeled flux $\left(H_{L}\right.$ or $H_{s}$ in this case) as a function of $U_{\mathrm{N} 10}$. Call these ratios $R_{L}$ and $R_{S}$, respectively, for latent and sensible heat flux.

If COARE version 2.6 were adequate for explaining the HEXOS and FASTEX heat fluxes, the measured/ modeled ratios would average one, and the ratios would show no dependence on wind speed-that is, the correlation coefficients in Fig. 3 would be zero. But both panels in Fig. 3 fail both tests: COARE version 2.6 explains neither the magnitude nor the wind speed dependence of the combined HEXOS-FASTEX set. To put these conclusions on a firm statistical footing, we test whether the averages of the ratios in Fig. 3 are statistically different from one and whether the correlation coefficients are statistically different from zero.

Any elementary statistics text explains that, if the sample size $N$ is large enough, the statement

$$
\mu-\frac{z_{\delta / 2} s}{\sqrt{N}} \leq \bar{x} \leq \mu+\frac{z_{\delta / 2} s}{\sqrt{N}}
$$

represents a $(1-\delta) 100 \%$ confidence interval for the sample mean $\bar{x}$. Here also, $s$ is the sample standard deviation, and $z_{\delta / 2}$ is the $(1-\delta / 2) 100$ percentage point of a normal distribution. In our case, we test the hypothesis that $\mu=1.00$ at the $1 \%$ significance level (so $\delta=0.01$ and $z_{\delta / 2}=2.576$ ).

For the latent heat flux panel in Fig. 3 (where $N=486$ ), the $99 \%$ confidence interval on the average of $R_{L}$, from (4.1), is [0.965,1.035]. For the sensible heat flux panel (where $N=337$ ), the $99 \%$ confidence interval for the average of $R_{S}$ is $[0.944,1.056]$. From the values listed in the caption for Fig. 3, we see that both latent and sensible heat flux average ratios are far outside these $99 \%$ confidence intervals. We thus establish statistically that an algorithm that includes only inter-
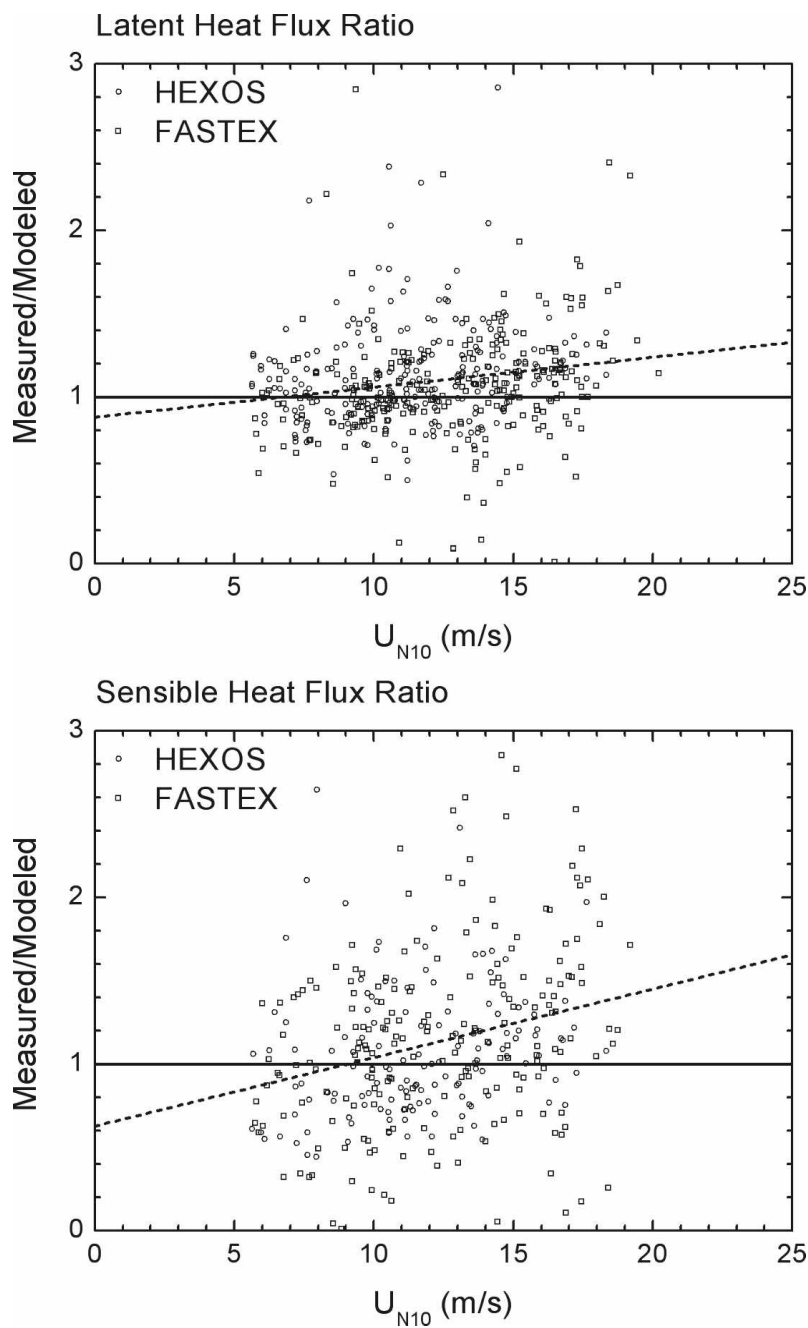

FIG. 3. Ratios of HEXOS and FASTEX measurements of the latent and sensible heat fluxes and the corresponding fluxes modeled with a strictly interfacial flux algorithm (i.e., COARE version 2.6; see appendix A). Here, $U_{\mathrm{N} 10}$ is the neutral-stability wind speed at $10 \mathrm{~m}$. The dashed line in each panel represents the best fit to the data. In the latent heat flux plot, the ratio average is 1.094 and the correlation coefficient is 0.176 ; in the sensible heat flux plot, the average is 1.124 , and the correlation coefficient is 0.274 .

facial transfer-that is, COARE version 2.6-cannot explain the magnitude of the HEXOS and FASTEX heat fluxes.

Likewise, Bendat and Piersol (1971, 126ff.) describe the distribution for the sample correlation coefficient $r_{\mathrm{xy}}$ between two variables $x$ and $y$. Briefly, if the sample is large enough, the statistic

$$
\omega=\frac{1}{2} \ln \left(\frac{1+r_{\mathrm{xy}}}{1-r_{\mathrm{xy}}}\right)
$$

has a normal distribution with mean 


$$
\mu_{\omega}=\frac{1}{2} \ln \left(\frac{1+\rho_{\mathrm{xy}}}{1-\rho_{\mathrm{xy}}}\right)
$$

and variance

$$
\sigma_{\omega}^{2}=\frac{1}{N-3}
$$

In (4.3), $\rho_{\mathrm{xy}}$ is the true correlation coefficient. With this formalism, a $(1-\delta) 100 \%$ confidence interval for $\omega$ is

$$
-z_{\delta / 2} \leq \frac{\omega-\mu_{\omega}}{\sigma_{\omega}} \leq z_{\delta / 2} .
$$

Because we are testing the hypothesis that $\rho_{\mathrm{xy}}=0$, $\mu_{\omega}=0$ from (4.3). We further rearrange (4.5) to obtain the following $(1-\delta) 100 \%$ confidence interval for $r_{\mathrm{xy}}$ :

$$
\frac{\exp \left(-2 z_{\delta / 2} \sigma_{\omega}\right)-1}{\exp \left(-2 z_{\delta / 2} \sigma_{\omega}\right)+1} \leq r_{\mathrm{xy}} \leq \frac{\exp \left(2 z_{\delta / 2} \sigma_{\omega}\right)-1}{\exp \left(2 z_{\delta / 2} \sigma_{\omega}\right)+1} .
$$

Again, testing at the $1 \%$ significance level, we calculate the $99 \%$ confidence interval for the correlation coefficient in the latent heat flux panel in Fig. 3 to be $[-0.117,0.117]$, and for the sensible heat flux panel, $[-0.140,0.140]$. Because the correlation coefficients mentioned in the caption for Fig. 3 are far outside these intervals, we confirm that an algorithm that models only interfacial transfer cannot explain the wind speed behavior of the combined HEXOS-FASTEX dataset. We thus reject the null hypothesis that a state-of-the-art interfacial flux algorithm is adequate for representing the HEXOS and FASTEX data.

\section{b. With spray}

When faced with a dilemma similar to that presented in Fig. 3-the heat flux measurements were larger than the model predictions at high wind speeds-Fairall et al. (2003, their Fig. 4) assumed that the model parameterizations for the scalar roughness lengths $z_{T}$ and $z_{Q}$ [see (A.2b) and (A.2c)] were inadequate. Accordingly, they tuned new $z_{T}$ and $z_{Q}$ parameterizations to their data and continued assuming implicitly that the turbulent heat fluxes occurred strictly through interfacial processes all the way up to wind speeds of $20 \mathrm{~m} \mathrm{~s}^{-1}$.

Although this is a reasonable operational approach, our earlier work-both theoretical and data-basedsuggests that the spray route is significant for air-sea heat transfer when the $10-\mathrm{m}$ wind speed reaches 12 $15 \mathrm{~m} \mathrm{~s}^{-1}$ (Andreas 1992; Andreas et al. 1995; Andreas and DeCosmo 2002). Figure 3 emphasizes this point. Both $R_{S}$ and $R_{L}$ are centered around one and show no obvious wind speed dependence for wind speeds up to $10 \mathrm{~m} \mathrm{~s}^{-1}$, the wind speed range over which COARE 2.6 has been validated. In both panels in Fig. 3, however,

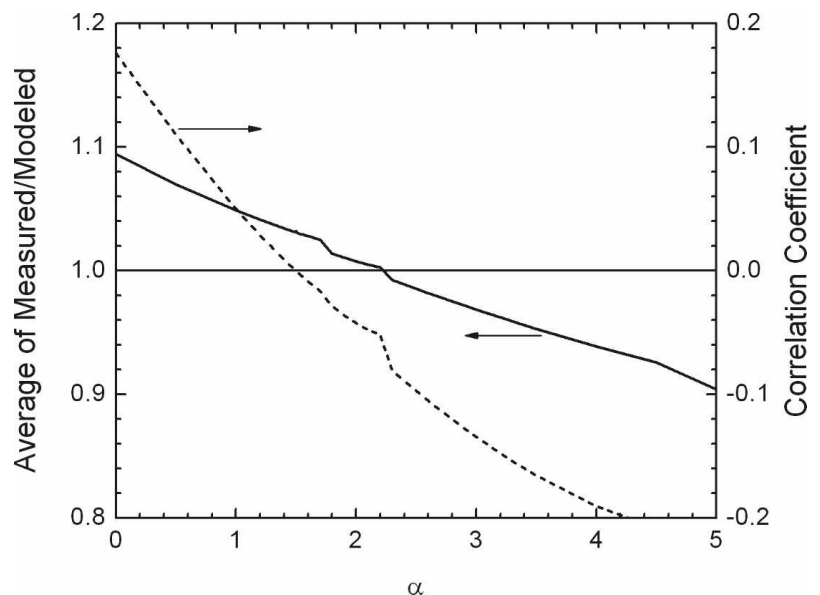

FIG. 4. Evaluating $\alpha$ in (2.9a) from the combined HEXOS and FASTEX set of measured latent heat fluxes. The left vertical axis is the average of measured-to-modeled values of the latent heat flux (i.e., the average of $R_{L}$; solid line); the right axis is the correlation coefficient between $R_{L}$ and $U_{\mathrm{N} 10}$ (dashed line). The correct $\alpha$ value produces an average near one and a correlation coefficient near zero.

the data collected in wind speeds above $10 \mathrm{~m} \mathrm{~s}^{-1}$ are responsible for the positive biases in the $R_{L}$ and $R_{S}$ averages and for the positive slopes with wind speed. We interpret this behavior as a signature of sea spray effects.

Of course, some unrecognized process-instead of spray-may be enhancing the heat fluxes, but in (2.9), we have a theoretical model with which to account for spray transfer. If this model can explain the HEXOS and FASTEX fluxes, we may not need to look for other transfer processes.

Accounting for spray effects starts with evaluating $\alpha$ in (2.9a). Again, we presume that the nominal spray latent heat flux $\bar{Q}_{L}$ is approximately correct; $\alpha$ should then be of order one. We estimate $\alpha$ from the HEXOS and FASTEX data and have two methods for judging the best $\alpha$ value. As we saw with Fig. 3, we want the average of the $R_{L}$ ratios to be near one and the correlation coefficient of $R_{L}$ with $U_{\mathrm{N} 10}$ to be near zero. Figure 4 shows these two metrics as $\alpha$ increases from 0 to 5 .

In Fig. 4, the correlation coefficient is zero and the least squares fitting line is thus horizontal for $\alpha=1.5$. The figure also shows that, there, the average of the $R_{L}$ ratios is 1.03 , which, according to the discussion in section $4 \mathrm{a}$, is not statistically different from 1.00 . Hence, we adopt $\alpha=1.5$.

Evaluating $\beta$ and $\gamma$ in (2.9b) is not as straightforward, however. Again, we want to obtain an average value for the ratio of measured-to-modeled sensible heat flux (i.e., average of $R_{S}$ ) near one and a correlation coeffi- 
cient between $R_{S}$ and $U_{\mathrm{N} 10}$ near zero. By varying $\beta$ and $\gamma$ over a range of plausible values, we settled on $\beta=10.5$ and $\gamma=0.2$. These values, of course, depend on our original choice of $\alpha$; but Fig. 4 is unequivocal that $\alpha=1.5$ will produce the most satisfying latent heat flux results.

This combination of $\alpha, \beta$, and $\gamma$ values produces an average value for $R_{S}$ of 0.98 and an $R_{S}-U_{\mathrm{N} 10}$ correlation coefficient of 0.072 . The statistical tests described in the last subsection confirm that this $R_{S}$ average is not statistically different from 1.00 and that the correlation coefficient is not statistically different from 0.00 . We thus adopt $\beta=10.5$ and $\gamma=0.2$ for use in (2.9b).

Viewed in the context of the enthalpy flux, (2.10), this small $\gamma$ value tends to confirm Andreas and Emanuel's (2001) conclusion that the spray sensible heat flux is the primary route by which spray affects storm energy. The spray latent heat flux appears in (2.10) only as the small feedback term $\gamma \bar{Q}_{L}$ that arises because the evaporating spray cools the near-surface air and thereby enhances the air-sea temperature difference.

Figure 5 is like Fig. 3, but in it, instead, we include spray effects in the modeled heat fluxes through (2.9) and the $\alpha, \beta$, and $\gamma$ values that we just found. In the latent heat flux panel, the least squares line is horizontal; that is, the $R_{L}$ values have no wind speed dependence. In the sensible heat flux panel, the least squares line has a slight positive slope that is not statistically different from zero. In each panel, the average of the plotted points is not statistically different from 1.00. In other words, the modeled fluxes are unbiased.

Figure 5 also highlights cases with at least a $10 \%$ spray contribution. That is, in the latent heat flux panel, filled markers denote cases for which $\left|\alpha \bar{Q}_{L} / H_{L}\right| \geq 0.1$; in the sensible heat flux panel, filled markers denote $\left|\left[\beta \bar{Q}_{S}-(\alpha-\gamma) \bar{Q}_{L}\right] / H_{S}\right| \geq 0.1$. In the latent heat flux panel, most cases with $U_{\mathrm{N} 10}>13 \mathrm{~m} \mathrm{~s}^{-1}$ include at least a $10 \%$ spray effect. In the sensible heat flux panel, almost all cases for which $U_{\mathrm{N} 10}>11 \mathrm{~m} \mathrm{~s}^{-1}$ include at least a $10 \%$ spray effect.

To recap, we first showed that a state-of-the-art bulk flux algorithm that treats only interfacial fluxes can explain neither the magnitude nor the wind speed dependence of the combined HEXOS-FASTEX heat fluxes. But by complementing this interfacial flux algorithm with a theoretically based model that explicitly accounts for spray-mediated transfer, we have explained both the magnitude and the wind speed dependence of the HEXOS-FASTEX set. This analysis also lets us separate the measured fluxes into interfacial and spray contributions and thereby establishes that spraymediated fluxes become significant (at least a $10 \%$ ef-

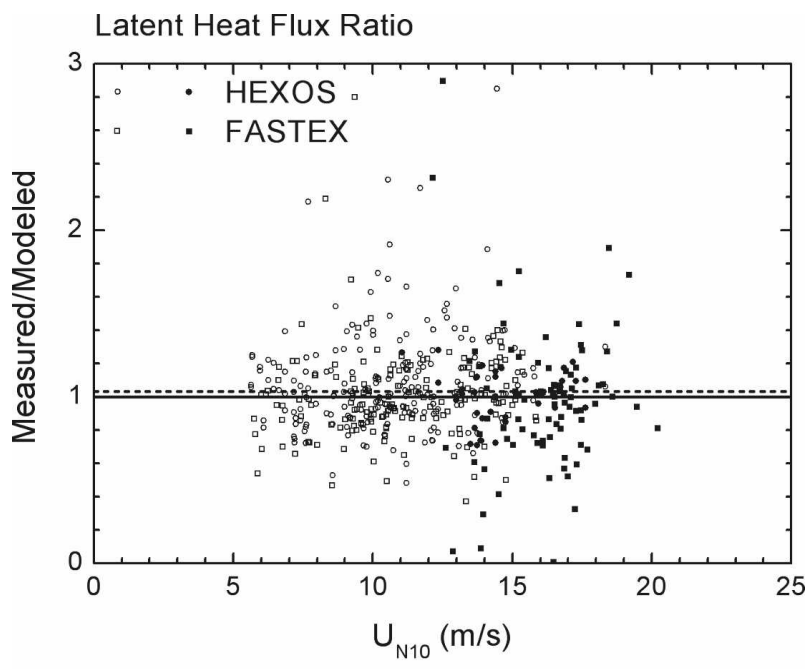

Sensible Heat Flux Ratio

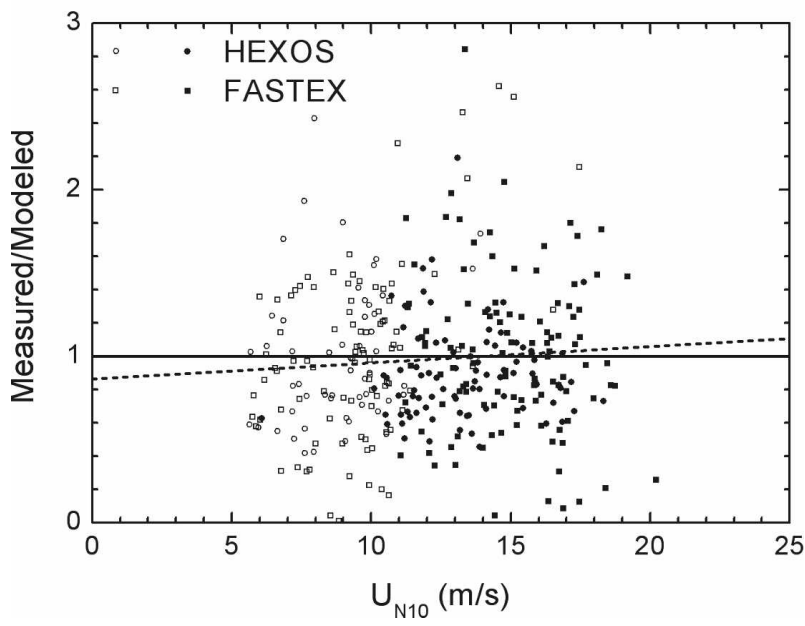

FIG. 5. Same as in Fig. 3, but here we include spray in the modeled heat fluxes through (2.9) with $\alpha=1.5, \beta=10.5$, and $\gamma=0.2$. In the latent heat flux panel, the average of the plotted ratios is 1.031 , and the $R_{L}-U_{\mathrm{N} 10}$ correlation coefficient is 0.000 ; in the sensible heat flux panel, the average of the ratios is 0.980 , and the $R_{S}-U_{\mathrm{N} 10}$ correlation coefficient is 0.072 . The filled markers denote cases for which the modeled spray contribution [the $\alpha, \beta$, and $\gamma$ terms in (2.9)] sum to at least $10 \%$ of the corresponding modeled interfacial contribution (the $H_{s}$ and $H_{L}$ terms).

fect) in this dataset when the $10-\mathrm{m}$ wind speed reaches $11-13 \mathrm{~m} \mathrm{~s}^{-1}$.

\section{Spray flux algorithm}

The microphysical model that produced the spray fluxes $\bar{Q}_{S}$ and $\bar{Q}_{L}$ in (2.9) is too complex and too computer intensive for use in large-scale models. One of our purposes here, then, is to develop a fast spray flux algorithm comparable in speed to the COARE version 2.6 algorithm that we use to compute $H_{s}$ and $H_{L}$ 


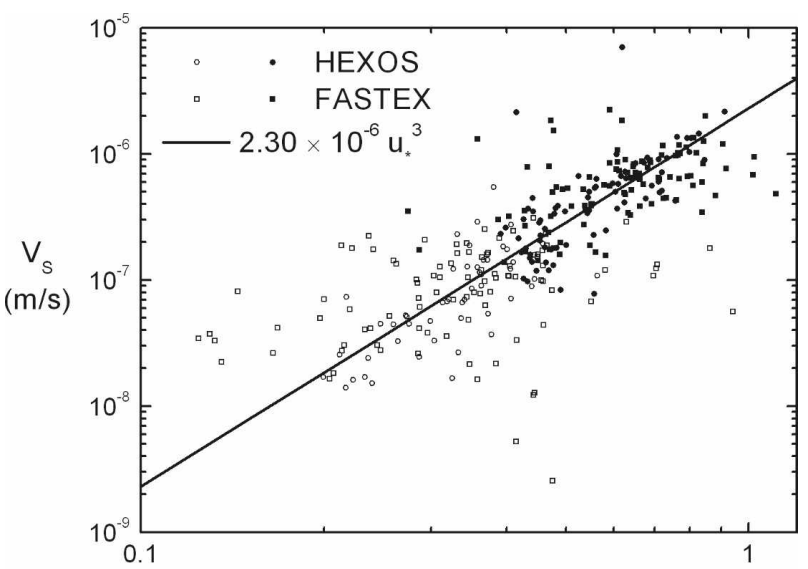

$\mathrm{u}_{*}(\mathrm{~m} / \mathrm{s})$

FIG. 6. The wind function $V_{S}$ defined by (5.2) and obtained from the HEXOS and FASTEX data. Filled markers are as in Fig. 5. The line represents (5.3).

in (2.9). The flux partitioning that went into our producing Fig. 5 is the basis for this new spray flux algorithm.

Equation (2.4) suggests that the sensible heat flux carried by all droplets of initial radius $r_{0}$ scales with $\rho_{s} c_{\mathrm{ps}}\left(T_{s}-T_{\mathrm{eq}}\right)$ because the droplet residence time $\tau_{f}$ is usually much longer than the temperature evolution time $\tau_{T}$. Furthermore, Fig. 2 shows that droplets with initial radii near $100 \mu \mathrm{m}$ contribute most to $\bar{Q}_{S}$. Hence, as a simple model, we assume that these $100-\mu \mathrm{m}$ droplets are the bellwethers of the spray sensible heat flux; thus we model it as

$$
Q_{S, \mathrm{sp}} \equiv \beta \bar{Q}_{S}-(\alpha-\gamma) \bar{Q}_{L}=\rho_{s} c_{\mathrm{ps}}\left(T_{s}-T_{\mathrm{eq}, 100}\right) V_{S}\left(u_{*}\right) .
$$

Here, $Q_{S, \mathrm{sp}}$ is given in $\mathrm{W} \mathrm{m}^{-2} ; T_{\mathrm{eq}, 100}$ is the equilibrium temperature of these $100-\mu \mathrm{m}$ droplets; and $V_{S}\left(u_{*}\right)$ is a wind function that we parameterize in terms of the friction velocity $u_{*}$. Using $u_{*}$ rather than wind speed as the argument in $V_{S}$ recognizes it as a more dynamically important variable.

We evaluate $V_{S}\left(u_{*}\right)$ from the spray sensible heat fluxes that we found in the last section. Figure 6 shows

$$
V_{S}\left(u_{*}\right) \equiv \frac{\beta \bar{Q}_{S}-(\alpha-\gamma) \bar{Q}_{L}}{\rho_{s} c_{\mathrm{ps}}\left(T_{s}-T_{\mathrm{eq}, 100}\right)}
$$

for the combined HEXOS-FASTEX set, where we computed $T_{\text {eq, } 100}$ from Andreas's (2005a) fast microphysical algorithm. The data follow a power-law relation with a correlation coefficient of 0.69 and thus confirm that (5.1) is a reasonable parameterization for the spray sensible heat flux. We obtain

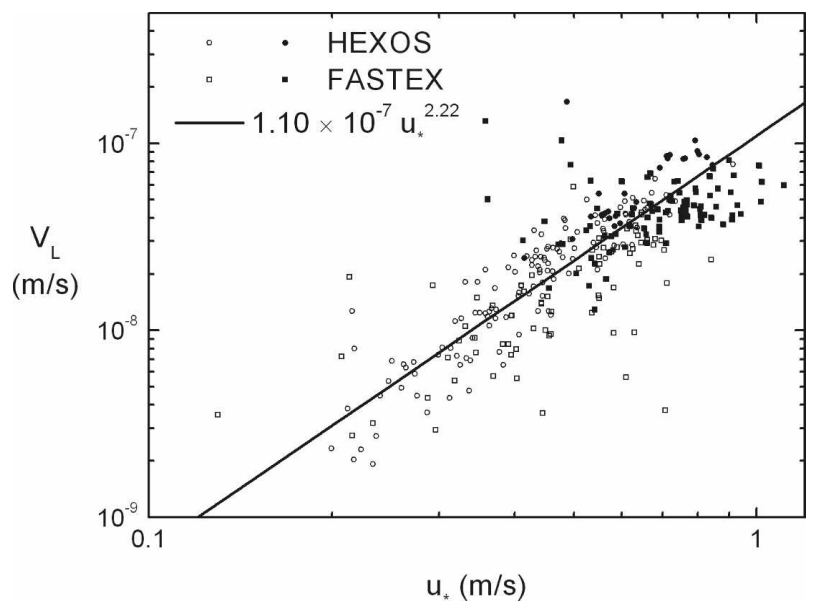

FIG. 7. Same as in Fig. 6, but for the wind function $V_{L}$ defined by (5.5). The line represents (5.6).

$$
V_{S}\left(u_{*}\right)=2.30 \times 10^{-6} u_{*}^{3},
$$

where $V_{S}$ is in $\mathrm{m} \mathrm{s}^{-1}$ for $u_{*}$ in $\mathrm{m} \mathrm{s}^{-1}$. In Fig. 6, almost all cases for which $u_{*}$ is greater than $0.4 \mathrm{~m} \mathrm{~s}^{-1}$ display at least a $10 \%$ spray effect in the sensible heat flux.

We follow similar reasoning to obtain a parameterization for the spray latent heat flux. Equation (2.6a) implies that the spray latent heat flux mediated by all droplets of initial radius $r_{0}$ scales as $\rho_{s} L_{v}\left\{1-\left[r\left(\tau_{f}\right) / r_{0}\right]^{3}\right\}$. Moreover, Fig. 2 shows that droplets with initial radii near $50 \mu \mathrm{m}$ contribute most to $\bar{Q}_{L}$. As a simple parameterization, we therefore hypothesize that these $50-\mu \mathrm{m}$ droplets are good indicators of the total spray latent heat flux and model it as

$$
Q_{L, \mathrm{sp}} \equiv \alpha \bar{Q}_{L}=\rho_{s} L_{v}\left\{1-\left[\frac{r\left(\tau_{f, 50}\right)}{50 \mu \mathrm{m}}\right]^{3}\right\} V_{L}\left(u_{*}\right)
$$

Here, $Q_{L, \mathrm{sp}}$ is in $\mathrm{W} \mathrm{m}^{-2} ; \tau_{f, 50}$ is the approximate residence time for droplets with an initial radius of $50 \mu \mathrm{m}$, which we compute from $(2.8) ; r\left(\tau_{f, 50}\right)$ is the radius these droplets have when they fall back into the sea [see (2.5)]; and the $50 \mu \mathrm{m}$ reiterates our hypothesis that $50-\mu \mathrm{m}$ droplets lead the spray latent heat flux.

Equation (5.4) introduces another wind function $V_{L}$, which we define as

$$
V_{L}\left(u_{*}\right) \equiv \frac{\alpha \bar{Q}_{L}}{\rho_{s} L_{v}\left\{1-\left[r\left(\tau_{f, 50}\right) / 50 \mu \mathrm{m}\right]^{3}\right\}} .
$$

Figure 7 shows how we evaluated this function from the HEXOS and FASTEX data. To obtain $r\left(\tau_{f, 50}\right)$ in (5.5), we used Andreas's (2005a) fast microphysical algorithms to compute $r_{\mathrm{eq}, 50}$ and $\tau_{r, 50}$ in (2.5); these are, respectively, the equilibrium radius of a droplet that 
starts with a radius of $50 \mu \mathrm{m}$ and the time scale for reaching that equilibrium radius.

As with $V_{S}, V_{L}$ follows a power law in $u_{*}$. Our result is

$$
V_{L}\left(u_{*}\right)=1.10 \times 10^{-7} u_{*}^{2.22},
$$

which gives $V_{L}$ in $\mathrm{m} \mathrm{s}^{-1}$ when $u_{*}$ is in $\mathrm{m} \mathrm{s}^{-1}$. The clustering of the data in Fig. 7 around this power law and the correlation coefficient of the fit, 0.80 , supports our parameterization in (5.4). In Fig. 7, most cases for which $u_{*}$ is greater than $0.6 \mathrm{~m} \mathrm{~s}^{-1}$ include at least a $10 \%$ spray effect in the latent heat flux.

The functions $V_{S}$ and $V_{L}$ in (5.3) and (5.6), respectively, are not strictly comparable to analogous functions that Andreas (2004a) derived from the HEXOS data alone because Andreas used a full microphysical model to compute the $T_{\text {eq,100 }}, r_{\text {eq,50, }}$, and $\tau_{r, 50}$ values used in that fitting. Still, the consistency between our analysis and Andreas's is reassuring.

The $V_{S}$ function in (5.3) is exactly 2 times larger than the similar function in Andreas (2004a). That is, both functions have the same $u_{*}^{3}$ dependence. The $V_{L}$ function in (5.6) is smaller and has a weaker $u_{*}$ dependence than Andreas's comparable result, which was $V_{L}=2.65 \times 10^{-7} u_{*}^{2.61}$. Figure 7 explains the difference: the HEXOS data tend to be above the fitting line, and the FASTEX data tend to be below it. In both results, though, $V_{L}$ increases faster than the square of $u_{*}$.

Figure 2 suggest that the peaks in $Q_{S}$ and $Q_{L}$ actually change location with wind speed rather than being fixed near $r_{0}=100 \mu \mathrm{m}$ and $r_{0}=50 \mu \mathrm{m}$, respectively. In light of the uncertainty in the spray generation function, though, parameterizations that are more sophisticated than the one-size models in (5.1) and (5.4) are unwarranted. Obviously, choosing other radii than 100 and $50 \mu \mathrm{m}$ as our bellwethers for the spray transfer would change the functions $V_{S}$ and $V_{L}$, but the predicted fluxes $Q_{S, \text { sp }}$ and $Q_{L \text {,sp }}$ should be largely unaffected.

In summary, our spray flux algorithm for high-wind spray conditions converts from (2.9) to

$$
\begin{gathered}
H_{L, T}=H_{L}+Q_{L, \mathrm{sp}}, \\
H_{s, T}=H_{s}+Q_{S, \mathrm{sp}} .
\end{gathered}
$$

In this, the interfacial fluxes $H_{L}$ and $H_{s}$ come, basically, from the COARE version 2.6 algorithm, as described in appendix A. The spray-mediated sensible heat flux $Q_{S \text { sp }}$ comes from (5.1) and (5.3); the spray-mediated latent heat flux $Q_{L, \mathrm{sp}}$ comes from (5.4), (5.6), (2.5), and (2.8). The approximations reported in Andreas (2005a) provide the necessary microphysical variables $T_{\text {eq,100, }}$, $r_{\mathrm{eq}, 50}$, and $\tau_{r, 50}$.
As is typical in bulk flux algorithms, we solve for $H_{s}$ and $H_{L}$ iteratively. After the solution converges, we use the resulting value of $u_{*}$ to compute $V_{S}$ and $V_{L}$ from (5.3) and (5.6); that is, the interfacial and spray fluxes are as yet uncoupled. We identify the algorithm we describe here as version 3.1. That algorithm also includes a parameterization for how spray alters the near-surface stress profile (Andreas 2004b). Andreas (2003, 2004a), Andreas and Emanuel (2001), and Perrie et al. (2005) have described earlier versions of this algorithm.

We have redone the plots shown in Fig. 5 by substituting version 3.1 of our bulk spray flux algorithm for the full microphysical model we had used to make Fig. 5. These new plots look much the same as the corresponding plots in Fig. 5 and are, therefore, not shown here. In particular, in the latent heat flux plot, the average of $R_{L}$ is 1.033 and the $R_{L}-U_{\mathrm{N} 10}$ correlation coefficient is 0.023 (compared to 1.031 and 0.000 , respectively, in Fig. 5). In the sensible heat flux plot, the average of $R_{S}$ is 0.974 and the $R_{S}-U_{\mathrm{N} 10}$ correlation coefficient is 0.010 (compared to 0.980 and 0.072 , respectively, in Fig. 5). Thus, the bulk spray flux algorithm captures the main features of the full microphysical model's spray flux predictions but runs much faster.

To gauge the uncertainty in our new algorithm, we also plotted the HEXOS and FASTEX measurements of sensible and latent heat fluxes against predictions of these quantities from (5.7). For the sake of brevity, we do not show those figures but summarize the results. The best-fit lines through both scatterplots have slopes very near the 1:1 line, 1.014 for the sensible heat flux plot, and 1.034 for the latent heat flux plot. The biases between measured and modeled fluxes are $0.3 \mathrm{~W} \mathrm{~m}^{-2}$ for sensible heat flux and $5.7 \mathrm{~W} \mathrm{~m}^{-2}$ for latent heat flux. The correlation coefficient in the sensible heat flux plot is 0.80 and in the latent heat flux plot, 0.89 .

These fits between data and a bulk flux algorithm are typical of, if not better than, similar comparisons by Fairall et al. (1996b), Clayson et al. (1996), Zeng et al. (1998), Chang and Grossman (1999), and Brunke et al. (2002). We, however, treat wind speeds up to $20 \mathrm{~m} \mathrm{~s}^{-1}$ while none of these five studies included wind speeds above $13 \mathrm{~m} \mathrm{~s}^{-1}$. Fairall et al. (2003) did consider wind speeds up to $20 \mathrm{~m} \mathrm{~s}^{-1}$ but did not show scatterplots or report statistics that we can compare with ours.

\section{Sensitivity studies}

To highlight how the interfacial and spray contributions to the total air-sea heat and moisture fluxes scale differently, we show in Figs. 8-10 some sensitivity cal- 


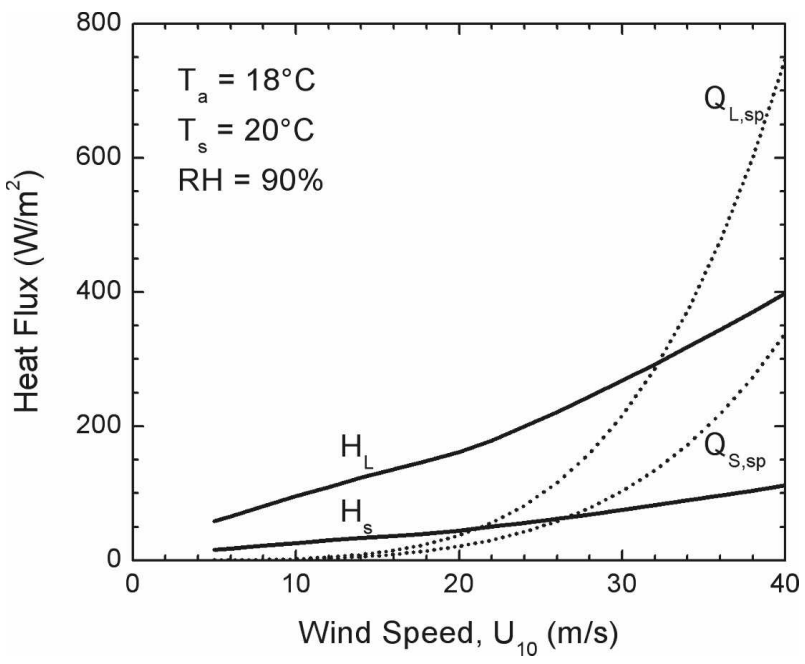

FIG. 8. Calculations made with the bulk flux algorithm described here of the interfacial $\left(H_{s}\right.$ and $\left.H_{L}\right)$ and spray $\left(Q_{S, \mathrm{sp}}\right.$ and $\left.Q_{L, \mathrm{sp}}\right)$ fluxes as functions of the $10-\mathrm{m}$ wind speed $U_{10}$. Air temperature is fixed at $18^{\circ} \mathrm{C}$, surface temperature is $20^{\circ} \mathrm{C}$, relative humidity is $90 \%$, sea surface salinity is $34 \mathrm{psu}$, barometric pressure is $1000 \mathrm{mb}$, and the water depth is $3000 \mathrm{~m}$.

culations based on our bulk flux algorithm. For the significant wave heights necessary for these calculations, we used Andreas and Wang's (2007) parameterization. Andreas (2004a) and Perrie et al. (2005) showed similar sensitivity plots based on earlier versions of our flux algorithm.

Figure 8 shows $H_{s}, H_{L}, Q_{S, \mathrm{sp}}$, and $Q_{L, \mathrm{sp}}$ as functions of wind speed for fixed relative humidity and air and surface temperatures. Realize that we are making these calculations for wind speeds well beyond the range for which our flux parameterizations have been tested. But because both the interfacial and spray flux parameterizations are theoretically based, we have some justification for these extrapolations. In fact, the theoretical basis for the heat flux parameterization in the COARE version 2.6 algorithm (i.e., Liu et al. 1979)—as opposed to the empirical basis in COARE version 3.0 (Fairall et al. 2003) - is the reason we use it in our algorithm.

The interfacial sensible and latent heat fluxes in Fig. 8 increase almost linearly with wind speed. The spray heat fluxes, on the other hand, are small for 10-m wind speeds less than about $12 \mathrm{~m} \mathrm{~s}^{-1}$ but then increase faster than the square of the wind speed because of (5.3) and (5.6). Because $Q_{S \text {,sp }}$ and $Q_{L \text {,sp }}$ are small and increase approximately linearly with wind speed for speeds less than $20 \mathrm{~m} \mathrm{~s}^{-1}$, the COARE version 3.0 algorithm can be operationally successful by using interfacial scaling to parameterize the total latent and sensible heat fluxes in this wind speed range. But extrapolating that algorithm to winds speeds above $20 \mathrm{~m} \mathrm{~s}^{-1}$ is not appropriate

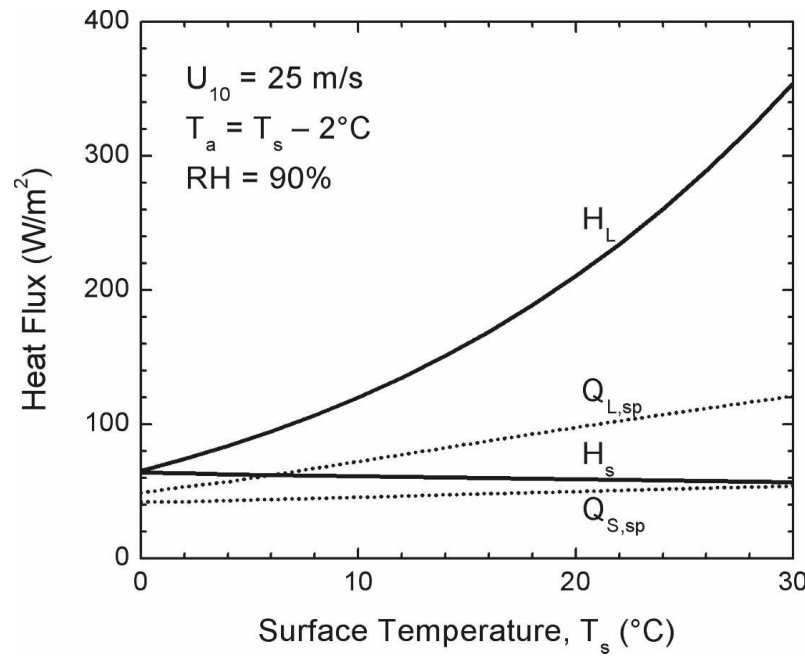

FIG. 9. Same as in Fig. 8, but the fluxes are plotted against surface temperature for the wind speed fixed at $25 \mathrm{~m} \mathrm{~s}^{-1}$. Again, the relative humidity is $90 \%$, but the air temperature is always $2^{\circ} \mathrm{C}$ less than the surface temperature.

because the nonlinear dependencies of $Q_{S, \mathrm{sp}}$ and $Q_{L \text {,sp }}$ on wind speed become significant.

Figure 9 shows a similar flux plot, but here the surface temperature varies from $0^{\circ}$ to $30^{\circ} \mathrm{C}$ with $U_{10}$ fixed at $25 \mathrm{~m} \mathrm{~s}^{-1}$. Again, this plot shows how the interfacial and spray fluxes scale differently. The interfacial latent heat flux, $H_{L}$, increases at a faster rate than linear with surface temperature because both $Q_{s}$ and $Q_{r}$ in (A.1c) are exponential functions of temperature. In contrast, the spray latent heat flux $Q_{L, \mathrm{sp}}$ increases nearly linearly with $T_{s}$ because $r_{\text {eq.50 }}$ in (2.5) does not depend strongly on temperature (Andreas 2005a) while $\tau_{r, 50}$, which

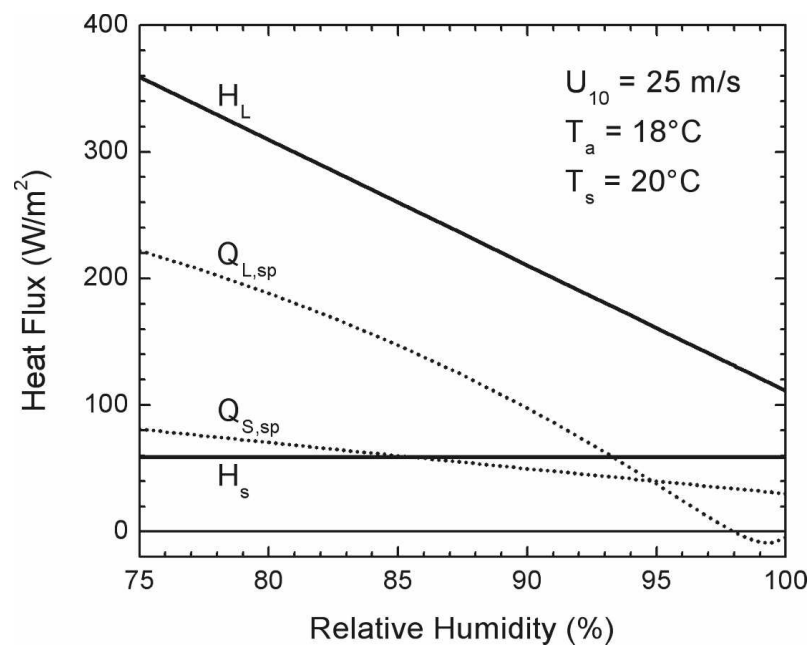

FIG. 10. Same as in Fig. 8, but the fluxes are plotted against relative humidity for the wind speed fixed at $25 \mathrm{~m} \mathrm{~s}^{-1}$. 
does, is compared with and comparable to $\tau_{f, 50}$ (Andreas 1992; Andreas and DeCosmo 1999).

The interfacial and spray sensible heat fluxes in Fig. 9 are both approximately linear in surface temperature, but $H_{s}$ decreases slightly with increasing $T_{s}$ while $Q_{S \text {,sp }}$ increases slightly. The decrease in $H_{s}$ is basically because the air density decreases with increasing temperature. The increase in $Q_{S \text {,sp }}$ results because the value of $T_{s}-T_{\text {eq, } 100}$ [see (5.1)] increases with increasing temperature (Andreas 1995) faster than the product $\rho_{s} c_{\mathrm{ps}}$ decreases (Andreas 2005b). Hence, again, because $H_{s}$ and $Q_{S \text {,sp }}$ scale differently over extended ranges in parameter space, it is not wise to parameterize the total sensible heat flux using interfacial scaling.

Figure 10 is the last sensitivity plot. This shows how the fluxes depend on relative humidity for the range of relative humidities over which our microphysical model is valid, $75-100 \%$. In the figure, both the interfacial and spray latent heat fluxes decrease with increasing relative humidity. The interfacial flux $H_{L}$ is essentially linear in relative humidity and stays positive through the range of humidities because $T_{a}$ is always $2^{\circ} \mathrm{C}$ less than $T_{s}$ [see (A.1c)]. The value of $Q_{L, \mathrm{sp}}$, in contrast, is not linear in relative humidity and actually goes negative when the relative humidity is above about $98 \%$ because the salinity (34 psu) depresses the saturation vapor pressure over spray droplets. That is, at these high relative humidities, vapor can condense on the spray droplets.

Also in Fig. 10, the interfacial sensible heat flux is essentially independent of relative humidity. If the winds were much weaker, $H_{\mathrm{s}}$ could depend weakly on relative humidity through stratification effects. For a wind speed of $25 \mathrm{~m} \mathrm{~s}^{-1}$, however, the surface layer stratification is nearly neutral. The spray sensible heat flux $Q_{S, \text { sp }}$ does decrease with increasing relative humidity, however. This behavior results because $T_{\text {eq,100 }}$ [see (5.1)] gets closer and closer to the air temperature $T_{a}$ as the relative humidity increases toward 98\% (Andreas 1995).

In summary, Fig. 10 reiterates that using interfacial scaling over an extended parameter space in which spray can make significant contributions to the heat fluxes is not appropriate. Treating the interfacial and spray fluxes separately, as we do in (2.9) and (5.7), is a more sound approach.

\section{Conclusions}

Theoretical studies (Andreas 1992, 1998; Andreas et al. 1995) and our earlier analysis of the flux data from HEXOS (Andreas and DeCosmo 1999, 2002) suggest that spray-mediated fluxes can account for at least $10 \%$ of the air-sea sensible and latent heat fluxes once the $10-\mathrm{m}$ wind speed exceeds about $12 \mathrm{~m} \mathrm{~s}^{-1}$. Still, most current bulk air-sea flux algorithms acknowledge only the interfacial contributions to the air-sea sensible and latent heat fluxes (e.g., Fairall et al. 1996b, 2003; Zeng et al. 1998; Bourassa et al. 1999; Brunke et al. 2003). Such algorithms cannot be reliably extrapolated to storm winds because the spray and interfacial fluxes scale differently with wind speed and other meteorological variables. Among ocean storm models that have incorporated spray effects, the results have been mixed (Fairall et al. 1994; Kepert et al. 1999; Bao et al. 2000; Andreas and Emanuel 2001; Wang et al. 2001; Perrie et al. 2004, 2005; Zhang et al. 2006). Of these storm models, however, only those by Andreas and Emanuel (2001), Perrie et al. (2004, 2005), and Zhang et al. (2006) have spray parameterizations actually tuned with flux data because they derived from our earlier analysis of the HEXOS data.

In light of the need for a quick, reliable spray flux parameterization, we have thus added to our previous HEXOS analysis the much larger set of air-sea flux measurements from FASTEX, another very good highwind dataset. Applying microphysical theory and our knowledge of the spray generation function, we identified a spray signature in the combined HEXOSFASTEX set. As Andreas and DeCosmo (2002) did, we applied multiple tests to confirm these spray effects. First, we showed that a state-of-the-art bulk flux algorithm, COARE version 2.6, that parameterizes only interfacial transfer can explain neither the magnitude nor the wind speed dependence of either the measured sensible or latent heat fluxes in the combined HEXOSFASTEX set.

But by then adding a spray flux parameterization to the interfacial flux algorithm, we could explain both the magnitude and the wind speed dependence of the sensible and latent heat fluxes in our dataset. In essence, these calculations let us separate the measured sensible and latent heat fluxes into interfacial and spray contributions. As we had seen earlier, our current analysis revealed at least a $10 \%$ spray effect on the total sensible and latent heat fluxes at fairly modest wind speeds: for $10-\mathrm{m}$ wind speeds above about $11 \mathrm{~m} \mathrm{~s}^{-1}$ for the sensible heat flux, and for winds above about $13 \mathrm{~m} \mathrm{~s}^{-1}$ for the latent heat flux.

Because we based these calculations on a full microphysical model that is too time consuming for largescale or operational storm modeling, we developed a much simpler bulk flux algorithm for the spray heat fluxes that we identified. For the spray sensible heat flux, we based this algorithm on the behavior of droplets that start with radius $100 \mu \mathrm{m}$ because these seem to 
lead the spray sensible heat transfer (see Fig. 2). We likewise based the algorithm for the spray latent heat transfer on the behavior of droplets that are originally $50 \mu \mathrm{m}$ in radius. These droplets are near the peak in the radius-specific spray latent heat flux (see Fig. 2).

The key to this spray flux algorithm was evaluating the so-called wind functions $V_{S}$ and $V_{L}$ shown in (5.2) and (5.5) and in Figs. 6 and 7. Both of these functions increase faster than the square of the friction velocity $u_{*}-\mathrm{a}$ result that emphasizes why spray-mediated heat transfer becomes increasingly important in storm winds.

Examples of sensitivity calculations in Figs. 8-10 that are based on this new flux algorithm demonstrate further how the interfacial and spray fluxes scale differently. We intend with these figures to underscore the hazards of using interfacial scaling to parameterize heat fluxes measured in winds nominally above $11-13 \mathrm{~m} \mathrm{~s}^{-1}$. If the data were collected over limited ranges of humidity and air and surface temperatures, the analysis might look good. But extrapolating these results outside the ranges they represent could produce unreliable results because of differences in how the interfacial and spray fluxes scale.

We have developed FORTRAN code for our combined spray and interfacial bulk flux algorithm and are willing to share it. We want to close with one important caveat, though. Our spray flux algorithm is intimately tied to the COARE version 2.6 interfacial flux algorithm because, essentially, we obtained the spray fluxes that we used to develop the spray flux algorithm by subtracting COARE version 2.6 predictions of the interfacial fluxes from the measured HEXOS and FASTEX heat fluxes. This approach is the only way we have found to separate the spray and interfacial fluxes. Therefore, using equations for the spray flux algorithm that we give here or extracting just the spray flux algorithm from our FORTRAN code and combining it with a different bulk interfacial flux algorithm constitutes a misuse of our results. To use our spray flux algorithm to compute the spray-mediated fluxes requires also using the COARE version 2.6 interfacial flux algorithm to compute the interfacial fluxes. Appendix B provides other recommendations for implementing our algorithm.

Acknowledgments. The NOAA/OAR director's discretionary funds supported deploying scientific equipment and collecting data on the R/V Knorr. We thank the captain and crew of the Knorr for their professionalism, Bill Otto for providing the FASTEX wave heights, Chris Fairall for several useful discussions during the course of this project, and two anonymous re- viewers for their helpful comments. The Office of Naval Research supported ELA in this work with awards N0001406MP20089, N0001407M0142, and N000140810411, and the National Science Foundation supported JEH and POGP with award ATM-9727054.

\section{APPENDIX A}

\section{Interfacial Flux Algorithm}

We base our calculations of the interfacial sensible $\left(H_{s}\right)$ and latent $\left(H_{L}\right)$ heat fluxes and the momentum flux $(\tau)$ on the COARE version 2.6 algorithm (Fairall et al. 1996b). We prefer this version of the COARE algorithm to the more recent version (3.0; Fairall et al. 2003) because the predictions for the roughness lengths for temperature $\left(z_{T}\right)$ and humidity $\left(z_{Q}\right)$ in version 2.6 are based on the surface renewal theory of Liu et al. (1979) and are validated with data for wind speeds up to about $10 \mathrm{~m} \mathrm{~s}^{-1}$ (e.g., Fairall et al. 1996b; Grant and Hignett 1998; Chang and Grossman 1999; Brunke et al. 2002), where spray should have a negligible effect on the turbulent heat fluxes.

For version 3.0, on the other hand, Fairall et al. (2003) obtained empirical expressions for $z_{T}$ and $z_{Q}$ using flux data collected in winds up to $20 \mathrm{~m} \mathrm{~s}^{-1}$, where we suspect that spray contributions are significant. Because Fairall et al. used interfacial scaling throughout this wind speed range, their expressions for $z_{T}$ and $z_{Q}$ likely include entangled spray and interfacial effects. Because these two contributions do not scale the same, we do not believe the version $3.0 z_{T}$ and $z_{Q}$ predictions will be reliable when extrapolated to wind speeds above $20 \mathrm{~m} \mathrm{~s}^{-1}$.

The COARE algorithm is based on Monin-Obukhov similarity theory. The three interfacial fluxes are calculated as

$$
\begin{aligned}
\tau & \equiv \rho_{\mathrm{a}} u_{*}^{2}=\rho_{a} C_{\mathrm{Dr}} S_{r}^{2}, \\
H_{s} & =\rho_{a} c_{p} C_{\mathrm{Hr}} S_{r}\left(\Theta_{s}-\Theta_{r}\right), \quad \text { and } \\
H_{L} & =\rho_{a} L_{v} C_{\mathrm{Er}} S_{r}\left(Q_{s}-Q_{r}\right) .
\end{aligned}
$$

Here, (A.1a) defines the friction velocity $u_{*} ; S_{r}, \Theta_{r}$, and $Q_{r}$ are the effective wind speed, potential temperature, and specific humidity at reference height $r ; \Theta_{s}\left(=T_{s}\right)$ is the potential temperature at the water surface; and $Q_{s}$ is the specific humidity at the surface. Also in (A.1), $\rho_{a}$ is the air density; $c_{p}$, the specific heat of air at constant pressure; and $\mathrm{L}_{v}$, the latent heat of vaporization.

Monin-Obukhov similarity theory enters by providing a theoretical basis for specifying the transfer coefficients for momentum $\left(C_{\mathrm{Dr}}\right)$, sensible heat $\left(C_{\mathrm{Hr}}\right)$, and 
latent heat $\left(C_{\mathrm{Er}}\right)$ appropriate at height $r$, as shown below:

$$
\begin{aligned}
& C_{\mathrm{Dr}}=\frac{k^{2}}{\left[\ln \left(r / z_{0}\right)-\psi_{m}(r / L)\right]^{2}}, \\
& C_{\mathrm{Hr}}=\frac{k^{2}}{\left[\ln \left(r / z_{0}\right)-\psi_{m}(r / L)\right]\left[\ln \left(r / z_{T}\right)-\psi_{h}(r / L)\right]}, \\
& C_{\mathrm{Er}}=\frac{k^{2}}{\left[\ln \left(r / z_{0}\right)-\psi_{m}(r / L)\right]\left[\ln \left(r / z_{Q}\right)-\psi_{h}(r / L)\right]} .
\end{aligned}
$$

Here, $k(=0.40)$ is the von Kármán constant; $z_{0}$ is the roughness length for wind speed; $z_{T}$ and $z_{Q}$ are the roughness lengths for temperature and humidity that we have already discussed; and $\psi_{m}$ and $\psi_{h}$ are empirical stratification corrections that are functions of $r / L$, where $L$ is the Obukhov length. Equations (A.1) and (A.2) must be solved iteratively because they are coupled through $L$.

We invoke the gustiness parameterization in the COARE algorithm to estimate the effective wind speed $\left(S_{r}\right)$ in unstable stratification from the reported wind speed $\left(U_{r}\right)$ :

$$
S_{r}=\left(U_{r}^{2}+\beta_{g}^{2} w_{*}^{2}\right)^{1 / 2} .
$$

Here, $\beta_{g}=1.25$, and $w_{*}$ is Deardorff's (1970) convective velocity scale (Godfrey and Beljaars 1991). For stable stratification, we adopt the suggestion by Jordan et al. (1999) that a similar "windless" coefficient is necessary, but we express it as

$$
S_{r}=U_{r}+0.5 \operatorname{sech}\left(U_{r}\right) .
$$

This gives $S_{r}$ in $\mathrm{m} \mathrm{s}^{-1}$ when $U_{r}$ is in $\mathrm{m} \mathrm{s}^{-1}$. Equations (A.3) and (A.4) prevent a singularity when $U_{r}$ is near zero (cf. Godfrey and Beljaars 1991; Zeng et al. 1998), but $S_{r}$ and $U_{r}$ are essentially the same in (A4) when $U_{r}$ is $5 \mathrm{~m} \mathrm{~s}^{-1}$ or greater.

For $z_{0}$ in (A.2), the COARE algorithm (Fairall et al. 1996b, 2003) uses a smooth blending between an aerodynamically smooth flow and a Charnock relation (e.g., Zilitinkevich 1969; Smith 1988); that is,

$$
z_{0}=0.135 \frac{\nu}{u_{*}}+0.0185 \frac{u_{*}^{2}}{g} .
$$

Here, $z_{0}$ is in meters when $u_{*}$ is in $\mathrm{m} \mathrm{s}^{-1} ; \nu$, the kinematic viscosity of air, is in $\mathrm{m}^{2} \mathrm{~s}^{-1}$; and $g$, the acceleration of gravity, is in $\mathrm{m} \mathrm{s}^{-2}$. The COARE algorithm uses a coefficient of 0.11 in the first term on the right of
(A.5), but 0.135 agrees better with the known behavior of the flow speed profile in aerodynamically smooth flow (e.g., Andreas et al. 2006).

The COARE version 2.6 algorithm uses 0.011 for the coefficient of the second term on the right in (A.5). But for version 3.0, Fairall et al. (2003) allowed that coefficient to increase linearly from 0.011 to 0.018 as the $10-\mathrm{m}$ wind speed increases from 10 to $18 \mathrm{~m} \mathrm{~s}^{-1}$. We just use a constant value of 0.0185 for this coefficient, though, because this value is appropriate for the high wind speeds and young waves that are our focus (Wu 1982; Johnson et al. 1998).

Our interfacial flux algorithm differs from the COARE algorithm in other small ways. For $\psi_{m}$ and $\psi_{h}$ in (A.2), we use Paulson's (1970) functions in unstable stratification and Holtslag and De Bruin's (1988) in stable stratification, as recommended by Jordan et al. (1999) and Andreas (2002b). Because our focus is on high wind speeds, these functions will yield insignificantly different results from the COARE algorithm's functions (Fairall et al. 1996b, 2003). We also do not incorporate the cool-skin and warm-layer parameterizations that are hallmarks of the COARE algorithm under the assumption that, for the high winds that characterize our dataset, the true water surface temperature $T_{\mathrm{s}}$ is within the measurement uncertainty of the nearsurface bulk water temperature.

Finally, we do not allow values of the scalar roughness lengths $z_{T}$ and $z_{Q}$, computed from the Liu et al. (1979) theory, to be smaller than the mean free path of air molecules, nominally $7 \times 10^{-8} \mathrm{~m}$ (cf. Andreas and Emanuel 2001). Both $z_{T}$ and $z_{Q}$ fall to this level when $u_{*}$ exceeds $0.88 \mathrm{~m} \mathrm{~s}^{-1}$, approximately. Hence, this limit affected only one HEXOS run and only a few FASTEX runs.

\section{APPENDIX B}

\section{A Blended Flux Algorithm}

The bulk flux algorithm that we have developed is explicitly for high winds-those above, say, $10 \mathrm{~m} \mathrm{~s}^{-1}$. Although Fig. 5 demonstrates that it is valid down to wind speeds as low as $5 \mathrm{~m} \mathrm{~s}^{-1}$, some may want to implement this algorithm in a numerical model that also needs to treat even lower wind speeds. For such an application, we suggest a blending technique.

For example, use the full COARE version 2.6 algorithm to compute the turbulent fluxes in low winds. This algorithm includes modules to account for lowwind phenomena such as the cool skin and warm layer of the ocean (Fairall et al. 1996a) and convective con- 
tributions in the $\psi_{m}$ and $\psi_{h}$ functions in (A.2) (Fairall et al. 1996b). Let $\tau_{T, \text { lo }}, H_{s, T, 1 \mathrm{o}}$, and $H_{L, T, \text { lo }}$ be the total surface stress and turbulent surface heat fluxes computed with this low-wind algorithm and denote these fluxes in general as $F_{\mathrm{lo}}$. Let $\tau_{T, \mathrm{hi}}, H_{s, T, \mathrm{hi}}$, and $H_{L, T, \mathrm{hi}}$ be the corresponding total fluxes computed with our high-wind algorithm and denote these in general as $F_{\mathrm{hi}}$.

Define a blending function as

$$
\begin{aligned}
& f=0 \text { for } 0 \leq U_{10} \leq 8 \mathrm{~m} \mathrm{~s}^{-1}, \\
& f=\left(U_{10}-8\right) / 4 \text { for } 8<U_{10}<12 \mathrm{~m} \mathrm{~s}^{-1}, \\
& f=1 \text { for } 12 \mathrm{~m} \mathrm{~s}^{-1} \leq U_{10} .
\end{aligned}
$$

Then, we recommend computing a general turbulent flux $F$ for all wind conditions as

$$
F=(1-f) F_{\mathrm{lo}}+f F_{\mathrm{hi}} .
$$

That is, for $U_{10} \leq 8 \mathrm{~m} \mathrm{~s}^{-1}$, use only the low-wind flux estimates. For $U_{10} \geq 12 \mathrm{~m} \mathrm{~s}^{-1}$, use only our high-wind algorithm. In between these limits, blend the two flux estimates linearly.

\section{REFERENCES}

Andreas, E. L, 1989: Thermal and size evolution of sea spray droplets. CRREL Rep. 89-11, U.S. Army Cold Regions Research and Engineering Laboratory, $37 \mathrm{pp}$.

, 1990: Time constants for the evolution of sea spray droplets. Tellus, 42B, 481-497.

- 1992: Sea spray and the turbulent air-sea heat fluxes. $J$. Geophys. Res., 97, 11 429-11 441.

_ , 1994: Reply. J. Geophys. Res., 99, 14 345-14 350. , 1995: The temperature of evaporating sea spray droplets. $J$. Atmos. Sci., 52, 852-862.

- 1998: A new sea spray generation function for wind speeds up to $32 \mathrm{~m} \mathrm{~s}^{-1}$. J. Phys. Oceanogr., 28, 2175-2184.

$\ldots$, 2002a: A review of the sea spray generation function for the open ocean. Atmosphere-Ocean Interactions, Vol. 1, W. Perrie, Ed., WIT Press, 1-46.

$\longrightarrow$, 2002b: Parameterizing scalar transfer over snow and ice: A review. J. Hydrometeor., 3, 417-432.

- 2003: An algorithm to predict the turbulent air-sea fluxes in high-wind, spray conditions. Preprints, 12 th Conf. on Interaction of the Sea and Atmosphere, Long Beach, CA, Amer. Meteor. Soc., 3.4. [Available online at http://ams.confex.com/ ams/pdfpapers/52221.pdf.]

_ 2004a: A bulk air-sea flux algorithm for high-wind, spray conditions, version 2.0. Preprints, 13th Conf. on Interactions of the Sea and Atmosphere, Portland, ME, Amer. Meteor. Soc., P1.5. [Available online at http://ams.confex.com/ams/ pdfpapers/77949.pdf.]

_ 2004b: Spray stress revisited. J. Phys. Oceanogr., 34, 14291440.

— 2005 a: Approximation formulas for the microphysical properties of saline droplets. Atmos. Res., 75, 323-345.

- 2005b: Handbook of Physical Constants and Functions for Use in Atmospheric Boundary Layer Studies. ERDC/CRREL
Monogr., No. M-05-1, U.S. Army Cold Regions Research and Engineering Laboratory, $42 \mathrm{pp}$.

- and J. DeCosmo, 1999: Sea spray production and influence on air-sea heat and moisture fluxes over the open ocean. Air-Sea Exchange: Physics, Chemistry, and Dynamics, G. L. Geernaert, Ed., Kluwer, 327-362.

_, and K. A. Emanuel, 2001: Effects of sea spray on tropical cyclone intensity. J. Atmos. Sci., 58, 3741-3751.

— HEXOS turbulent heat flux data. Bound.-Layer Meteor., 103, 303-333.

— and S. Wang, 2007: Predicting significant wave height off the northeast coast of the United States. Ocean Eng., 34, 13281335.

, J. B. Edson, E. C. Monahan, M. P. Rouault, and S. D. Smith, 1995: The spray contribution to net evaporation from the sea: A review of recent progress. Bound.-Layer Meteor., 72, 3-52.

—_ K. J. Claffey, R. E. Jordan, C. W. Fairall, P. S. Guest, P. O. G. Persson, and A. A. Grachev, 2006: Evaluations of the von Kármán constant in the atmospheric surface layer. $J$. Fluid Mech., 559, 117-149.

— , P. O. G. Persson, and J. E. Hare, 2007: A bulk turbulent air-sea flux algorithm for high-wind, spray conditions. Preprints, 15th Conf. on Air-Sea Interaction, Portland, OR, Amer. Meteor. Soc., 13.4. [Available online at http://ams. confex.com/ams/pdfpapers/125065.pdf.]

Bao, J.-W., J. M. Wilczak, J.-K. Choi, and L. H. Kantha, 2000: Numerical simulations of air-sea interaction under high wind conditions using a coupled model: A study of hurricane development. Mon. Wea. Rev., 128, 2190-2210.

Bendat, J. S., and A. G. Piersol, 1971: Random Data: Analysis and Measurement Procedures. Wiley-Interscience, $407 \mathrm{pp}$.

Bourassa, M. A., D. G. Vincent, and W. L. Wood, 1999: A flux parameterization including the effects of capillary waves and sea state. J. Atmos. Sci., 56, 1123-1139.

Brunke, M. A., X. Zeng, and S. Anderson, 2002: Uncertainties in sea surface turbulent flux algorithms and data sets. J. Geophys. Res., 107, 3141, doi:10.1029/2001JC000992.

, C. W. Fairall, X. Zeng, L. Eymard, and J. A. Curry, 2003: Which bulk aerodynamic algorithms are least problematic in computing ocean surface turbulent fluxes? J. Climate, 16, 619-635.

Businger, J. A., 1982: The fluxes of specific enthalpy, sensible heat, and latent heat near the earth's surface. J. Atmos. Sci., 39, 1889-1892.

Chang, H.-R., and R. L. Grossman, 1999: Evaluation of bulk surface flux algorithms for light wind conditions using data from the Coupled Ocean-Atmosphere Response Experiment (COARE). Quart. J. Roy. Meteor. Soc., 125, 1551-1588.

Clayson, C. A., C. W. Fairall, and J. A. Curry, 1996: Evaluation of turbulent fluxes at the ocean surface using surface renewal theory. J. Geophys. Res., 101, 28 503-28 513.

Clift, R., J. R. Grace, and M. E. Weber, 1978: Bubbles, Drops, and Particles. Academic Press, 380 pp.

Deardorff, J. W., 1970: Convective velocity and temperature scales for the unstable planetary boundary layer and for Rayleigh convection. J. Atmos. Sci., 27, 1211-1213.

DeCosmo, J., 1991: Air-sea exchange of momentum, heat and water vapor over whitecap sea states. Ph.D. dissertation, University of Washington, $212 \mathrm{pp}$.

- K. B. Katsaros, S. D. Smith, R. J. Anderson, W. A. Oost, K. Bumke, and H. Chadwick, 1996: Air-sea exchange of water 
vapor and sensible heat: The Humidity Exchange over the Sea (HEXOS) results. J. Geophys. Res., 101, 12 001-12 016.

Edson, J. B., and E. L Andreas, 1997: Modeling the role of sea spray on air-sea heat and moisture exchange. Preprints, 12th Symp. on Boundary Layers and Turbulence, Vancouver, BC, Canada, Amer. Meteor. Soc., 490-491.

—, S. Anquetin, P. G. Mestayer, and J. F. Sini, 1996: Spray droplet modeling. 2. An interactive Eulerian-Lagrangian model of evaporating spray droplets. J. Geophys. Res., 101, 1279-1293.

Emanuel, K. A., 1995: Sensitivity of tropical cyclones to surface exchange coefficients and a revised steady-state model incorporating eye dynamics. J. Atmos. Sci., 52, 3969-3976.

Fairall, C. W., J. D. Kepert, and G. J. Holland, 1994: The effect of sea spray on surface energy transports over the ocean. Global Atmos. Ocean Syst., 2, 121-142.

—, E. F. Bradley, J. S. Godfrey, G. A. Wick, J. B. Edson, and G. S. Young, 1996a: Cool-skin and warm-layer effects on sea surface temperature. J. Geophys. Res., 101, 1295-1308.

,-- D. P. Rogers, J. B. Edson, and G. S. Young, 1996b: Bulk parameterization of air-sea fluxes for Tropical OceanGlobal Atmosphere Coupled-Ocean Atmosphere Response Experiment. J. Geophys. Res., 101, 3747-3764.

,-- J. E. Hare, A. A. Grachev, and J. B. Edson, 2003: Bulk parameterization of air-sea fluxes: Updates and verification for the COARE algorithm. J. Climate, 16, 571-591.

Friedlander, S. K., 1977: Smoke, Dust, and Haze: Fundamentals of Aerosol Behavior. Wiley, 317 pp.

Godfrey, J. S., and A. C. M. Beljaars, 1991: On the turbulent fluxes of buoyancy, heat and moisture at the air-sea interface at low wind speeds. J. Geophys. Res., 96, 22 043-22 048.

Grant, A. L. M., and P. Hignett, 1998: Aircraft observations of the surface energy balance in TOGA-COARE. Quart. J. Roy. Meteor. Soc., 124, 101-122.

Holtslag, A. A. M., and H. A. R. De Bruin, 1988: Applied modeling of the nighttime surface energy balance over land. $J$. Appl. Meteor., 27, 689-704.

Johnson, H. K., J. Højstrup, H. J. Vested, and S. E. Larsen, 1998: On the dependence of sea surface roughness on wind waves. J. Phys. Oceanogr., 28, 1702-1716.

Joly, A., and Coauthors, 1997: The Fronts and Atlantic StormTrack Experiment (FASTEX): Scientific objectives and experimental design. Bull. Amer. Meteor. Soc., 78, 1917-1940.

Jordan, R. E., E. L Andreas, and A. P. Makshtas, 1999: Heat budget of snow-covered sea ice at North Pole 4. J. Geophys. Res., 104, 7785-7806.

Katsaros, K. B., and J. DeCosmo, 1990: Evaporation in high wind speeds, sea surface temperature at low wind speeds, examples of atmospheric regulation. Proc. Workshop on Modelling the Fate and Influence of Marine Spray, Marine Sciences Institute, University of Connecticut, Groton, CT, 106-114.

—_, and G. de Leeuw, 1994: Comment on "Sea spray and the turbulent air-sea heat fluxes" by Edgar L Andreas. J. Geophys. Res., 99, 14 339-14 343.

— S. D. Smith, and W. A. Oost, 1987: HEXOS—Humidity Exchange over the Sea: A program for research on water-vapor and droplet fluxes from sea to air at moderate to high wind speeds. Bull. Amer. Meteor. Soc., 68, 466-476.

- , and Coauthors, 1994: Measurements of humidity and temperature in the marine environment during the HEXOS main experiment. J. Atmos. Oceanic Technol., 11, 964-981.
Kepert, J., C. Fairall, and J.-W. Bao, 1999: Modelling the interaction between the atmospheric boundary layer and evaporating sea spray droplets. Air-Sea Exchange: Physics, Chemistry, and Dynamics, G. L. Geernaert, Ed., Kluwer, 363-409.

Liu, W. T., K. B. Katsaros, and J. A. Businger, 1979: Bulk parameterization of air-sea exchanges of heat and water vapor including the molecular constraints at the interface. J. Atmos. Sci., 36, 1722-1735.

Makin, V. K., 1998: Air-sea exchange of heat in the presence of wind waves and spray. J. Geophys. Res., 103, 1137-1152.

Mestayer, P. G., A. M. J. Van Eijk, G. de Leeuw, and B. Tranchant, 1996: Numerical simulation of the dynamics of sea spray over the waves. J. Geophys. Res., 101, $20771-$ 20797.

Paulson, C. A., 1970: The mathematical representation of wind speed and temperature profiles in the unstable atmospheric surface layer. J. Appl. Meteor., 9, 857-861.

Perrie, W., X. Ren, W. Zhang, and Z. Long, 2004: Simulation of extratropical Hurricane Gustav using a coupled atmosphereocean-sea spray model. Geophys. Res. Lett., 31, L03110, doi:10.1029/2003GL018571.

_ , E. L Andreas, W. Zhang, W. Li, J. Gyakum, and R. McTaggart-Cowan, 2005: Sea spray impacts on intensifying midlatitude cyclones. J. Atmos. Sci., 62, 1867-1883.

Persson, P. O. G., J. E. Hare, C. W. Fairall, and W. D. Otto, 2005: Air-sea interaction processes in warm and cold sectors of extratropical cyclonic storms observed during FASTEX. Quart. J. Roy. Meteor. Soc., 131, 877-912.

Smith, S. D., 1988: Coefficients for sea surface wind stress, heat flux, and wind profiles as a function of wind speed and temperature. J. Geophys. Res., 93, 15 467-15 472.

_ 1990: Influence of droplet evaporation on HEXOS humidity and temperature profiles. Proc. Workshop on Modelling the Fate and Influence of Marine Spray, Marine Sciences Institute, University of Connecticut, Groton, CT, 171-174.

_ efficients: The HEXOS results. Bound-Layer Meteor., 60, 109-142.

— , K. B. Katsaros, W. A. Oost, and P. G. Mestayer, 1996: The impact of the HEXOS programme. Bound.-Layer Meteor., 78, 121-141.

Van Eijk, A. M. J., B. S. Tranchant, and P. G. Mestayer, 2001: SeaCluse: Numerical simulation of evaporating sea spray droplets. J. Geophys. Res., 106, 2573-2588.

Wang, Y., J. D. Kepert, and G. J. Holland, 2001: The effect of sea spray evaporation on tropical cyclone boundary layer structure and intensity. Mon. Wea. Rev., 129, 2481-2500.

Wu, J., 1982: Wind-stress coefficients over sea surface from breeze to hurricane. J. Geophys. Res., 87, 9704-9706.

Zeng, X., M. Zhao, and R. E. Dickinson, 1998: Intercomparison of bulk aerodynamic algorithms for the computation of sea surface fluxes using TOGA COARE and TAO data. J. Climate, 11, 2628-2644.

Zhang, W., W. Perrie, and W. Li, 2006: Impacts of waves and sea spray on midlatitude storm structure and intensity. Mon. Wea. Rev., 134, 2418-2442.

Zilitinkevich, S. S., 1969: On the computation of the basic parameters of the interaction between the atmosphere and the ocean. Tellus, 21, 17-24. 